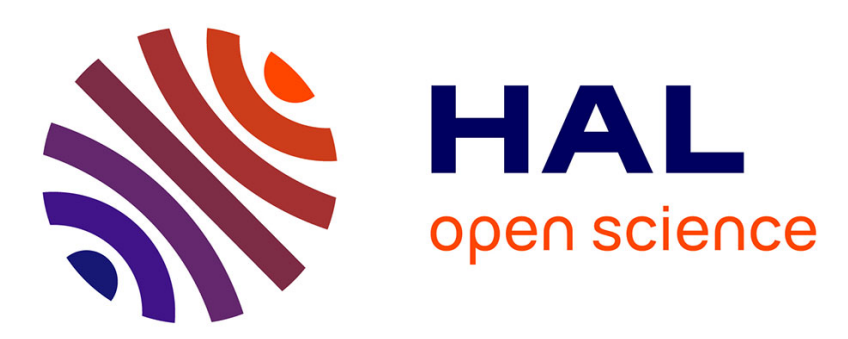

\title{
Le sanctuaire de Déméter à Vamiès (Itanos, Crète orientale). Topographie, architecture et petite plastique de terre cuite
}

Hélène Brun Kyriakidis, Alain Duplouy

\section{- To cite this version:}

Hélène Brun Kyriakidis, Alain Duplouy. Le sanctuaire de Déméter à Vamiès (Itanos, Crète orientale). Topographie, architecture et petite plastique de terre cuite. Bulletin de Correspondance Hellenique, 2014, 138, pp.201-244. hal-02404627

\section{HAL Id: hal-02404627 \\ https://hal.science/hal-02404627}

Submitted on 11 Dec 2019

HAL is a multi-disciplinary open access archive for the deposit and dissemination of scientific research documents, whether they are published or not. The documents may come from teaching and research institutions in France or abroad, or from public or private research centers.
L'archive ouverte pluridisciplinaire HAL, est destinée au dépôt et à la diffusion de documents scientifiques de niveau recherche, publiés ou non, émanant des établissements d'enseignement et de recherche français ou étrangers, des laboratoires publics ou privés. 
É C O L E F R A N ÇA I S E D'A T H È N E S
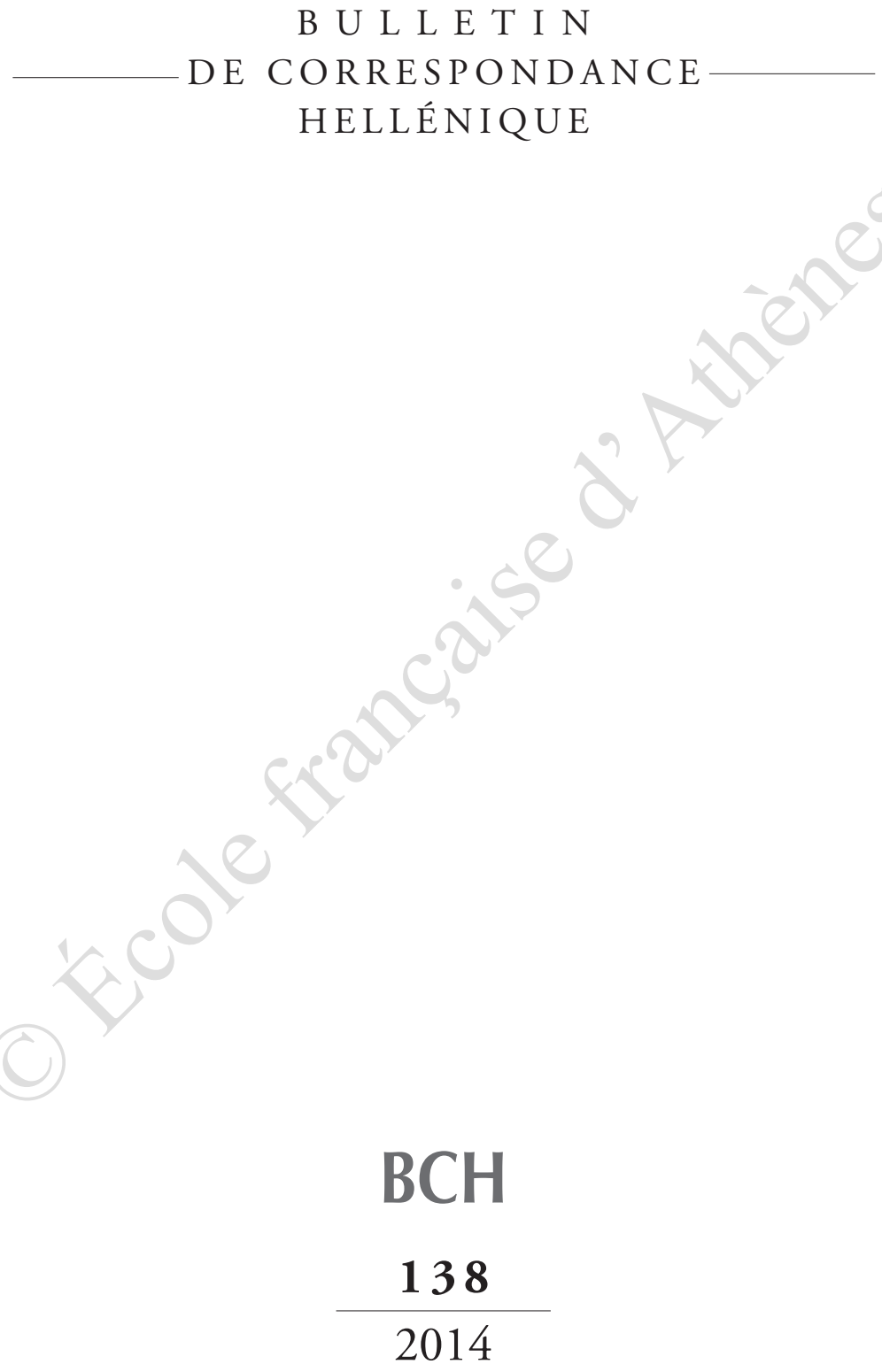


\title{
Le sanctuaire de Déméter à Vamiès (Itanos, Crète orientale)
}

\section{Topographie, architecture et petite plastique de terre cuite}

\author{
Hélène Brun, Alain DuplouY
}

Résumé La prospection du territoire d'Itanos a permis de repérer de nombreux sites, dont l'un fait l'objet du présent article : un petit sanctuaire situé en périphérie de la ville, à Vamiès, prospecté et nettoyé en 1996. Ces travaux avaient révélé les fondations d'un édifice rectangulaire et livré une abondante céramique ainsi qu'un lot de statuettes de terre cuite. Notre étude présente la topographie du sanctuaire et les statuettes qui y ont été recueillies. Ces dernières éclairent l'histoire du sanctuaire en donnant des pistes pour l'identification de la divinité qui y était vénérée (probablement Déméter). Leur étude stylistique qui fournit des indications sur l'origine de ces pièces invite aussi à les confronter aux autres dépôts découverts dans la région et à s'interroger sur la notion d'identité étéocrétoise appliquée à une production matérielle.

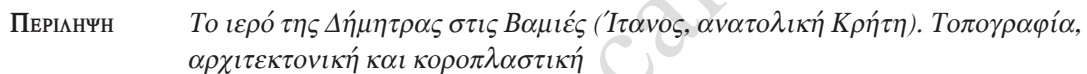

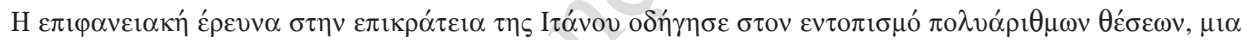

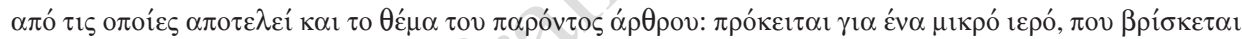

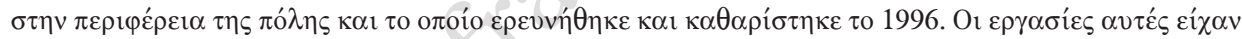

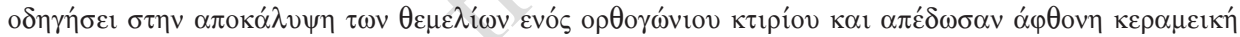

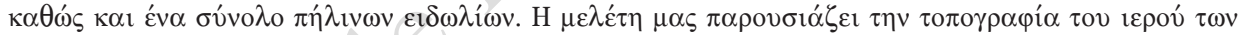

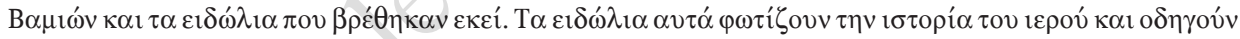

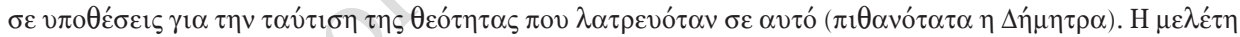

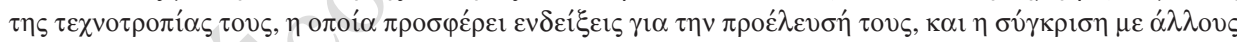

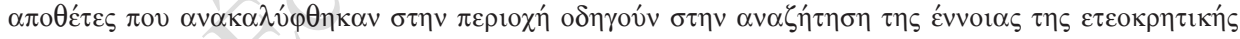

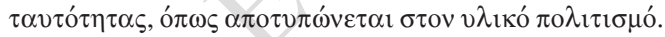

\section{Summary The sanctuary of Demeter at Vamies (Itanos, East Crete). Topography, architecture and small terracotta figurines}

The survey conducted on the territory of Itanos has led to the discovery of numerous sites. This paper focuses on a small sanctuary located in the immediate vicinity of the ancient town. The site was cleared of brushwood and intensively surveyed in 1996. This work revealed the foundations of a rectangular building and produced a lot of pottery and terracotta figurines. This paper offers a general presentation of the topography of the site, as well as a comprehensive catalogue and full discussion of the terracotta figurines. The latter offer various hints for the identification of the worshipped deity, probably Demeter, whereas the analysis of their stylistic features provide clues to the origin of these pieces, offering interesting parallels with other cult deposits in Eastern Crete. Finally, they allow examining the notion of Eteocretan identity when applied to material culture. 
À PROPOS DES AUTEURS

H. BRUn, université Paris-Sorbonne (Paris IV).

A. DuplouY, université Paris I-Panthéon-Sorbonne.

NOTE LIMINAIRE

Nous adressons nos remerciements à A. Barroche pour la réalisation des photographies des figurines, ainsi qu’à A. Zambon pour les dessins qu'elle en a faits. Nous remercions également Fr. Croissant, Chr. Mitsopoulou, J. Whitley et Th. Brisart pour leurs commentaires sur une version préliminaire de ce texte. Nous avons uni nos forces pour écrire cet article; l'étude des terres cuites et leur analyse stylistique sont dues à A. Duplouy; H. Brun, qui a organisé la prospection du site avec A. D’Hautcourt en 1996, s'est chargée de la partie topographique et de l'interprétation des ruines du sanctuaire. Ces travaux ont été effectués dans le cadre des recherches conduites à Itanos sous l'égide de l'École française d'Athènes.

ABRÉVIATIONS BIBLIOGRAPHIQUES

Erickson 2009 = Br. Erickson, "Roussa Ekklesia, Part 1: Religion and Politics in East Crete ", AJA 113, p. 353-404.

Pilz 2011 = O. Pilz, Frühe matrizengeformte Terrakotten aufKreta. Votivpraxis und Gesellschaftsstruktur in spätgeometrischer und früharchaischer Zeit.

Prent 2005 = M. Prent, Cretan Sanctuaries and Cults. Continuity and Change from Late Minoan IIIC to the Archaic Period.

SPORN 2002 = K. SPORN, Heiligtümer und Kulte Kretas in klassischer und hellenistischer Zeit. 
Depuis 1994, l'École française d'Athènes a repris l'exploration archéologique du site d'Itanos en Crète orientale. Si les travaux se sont principalement concentrés dans le secteur urbain, avec la fouille d'un quartier d'habitation, d'une basilique paléochrétienne et de la nécropole Nord, une campagne de prospection, dirigée par Alain Schnapp, a permis de situer ces vestiges dans un cadre territorial étendu ${ }^{1}$.

L'un des sites les plus intéressants de la prospection menée sur le territoire de la cité est un petit sanctuaire situé dans la périphérie immédiate de la ville antique ${ }^{2}$. Nous l'avions repéré dès 1994, sur les pentes de la colline de Vamiès et nous y avions effectué un nettoyage de surface et une prospection systématique en $1996^{3}$. Le nettoyage a révélé les soubassements d'un édifice rectangulaire, tandis que le nettoyage a livré un matériel très riche : une abondante céramique en général d'excellente qualité qui s'échelonne de l'époque géométrique au II $\mathrm{s}$. av. J.-C. au moins $s^{4}$, des lampes (parfois à becs multiples), ainsi que divers fragments de statuettes en terre cuite allant du viIe $s$. à la fin de l'époque hellénistique. Ces travaux ont permis de confirmer la nature cultuelle du site et ont fourni des indices sur sa chronologie. Les résultats préliminaires ont été présentés dans les chroniques de fouilles ${ }^{5}$, avant d'être repris dans des synthèses générales, comme celle que K. Sporn consacre aux sanctuaires et aux cultes crétois ${ }^{6}$.

Dans l'attente d'une publication complète et détaillée de l'ensemble du matériel de la prospection du territoire d'Itanos, nous souhaitons présenter ici le cadre architectural de ce petit sanctuaire, ainsi qu'une partie du matériel recueilli lors de la campagne de 1996. La petite plastique de Vamiès, à laquelle cette étude est plus spécifiquement consacrée, mérite en effet une attention particulière. Bien qu'il s'agisse de trouvailles de surface, cette collection de terres cuites informe en effet, dans une certaine mesure, sur les cultes qui étaient pratiqués dans le sanctuaire et sur l'histoire

1. Sur la prospection du territoire d'Itanos, A. Duplouy, A. Schnapp, A. Schnapp-Gourbeillon et al., "Recherches archéologiques à Itanos (Crète orientale) ", $R A$ (2009), p. 208-219, part. p. 214-219. Nous tenons à remercier A. Schnapp pour son encouragement à publier ce dossier sans attendre la publication des résultats de l'ensemble de la prospection.

2. Il est identifié comme le site "Vamiès 63 » dans la base de données de la prospection (http://prospection-itanos.efa.gr), mise en ligne sur le serveur de l'EFA depuis 2006. Sur cet outil et sur le SIG de la prospection, L. Costa, A. Duplouy, Fr. Eyraud et A. Sarris, «Vers la mise en réseau des données et des chercheurs : le système d'information de la prospection d'Itanos (Crète orientale) ", Archeologia e calcolatori 19 (2008), p. 103-122. Les fiches détaillées des sites et du matériel sont consultables en ligne sur autorisation.

3. $B C H 119$ (1995), p. 734; BCH 121 (1997), p. 820-822.

4. Ce matériel a été étudié par N. Massar et A. Tsingarida. Il fera l'objet d'une publication détaillée dans A. Schnapp (éd.), Le territoire d'Itanos, à paraître. En attendant, on peut en consulter le catalogue complet sur le site internet de la prospection d'Itanos (voir n. 2).

5. BCH 121 (1997), p. 820-822.

6. SPORn 2002, p. 36-37. 
de l'établissement. En outre, l'examen de leur style et l'analyse de la provenance de ces figurines, en rapport avec l'histoire de la cité d'Itanos, en particulier à l'époque archaïque, invitent à revenir sur la question de l'expression identitaire des cités de Crète de l'Est. Comme nous le verrons, si en l'état actuel de la documentation et de la recherche elles ne permettent pas de trancher un débat complexe, elles invitent au moins à en préciser les termes.

\section{PROSPECTION DU PLATEAU DE VAMIÈS, TOPOGRAPHIE ET ARCHITECTURE DU SANCTUAIRE}

Le site se présente comme un plateau (alt. moyenne : $33 \mathrm{~m}$ ) surélevé de plusieurs mètres par rapport au terrain environnant (fig. I, 2 et 3). Cette terrasse naturelle se limite à l'Est et au Nord par un abrupt ressaut du rocher; au Sud et à l'Ouest, le terrain est moins accidenté et suit une pente régulière vers le sommet de la colline de Vamiès. En contrebas, ouvrant vers l'Est et le Nord-Est, se trouvent de petites cavités emplies de sédiments; elles paraissent résulter d'un effondrement du plateau qui, anciennement, se serait étendu davantage de ce côté : en tout état de cause, on distingue bien, au Nord-Est surtout, des fragments rocheux partiellement détachés ou déjà tombés de la paroi.

La prospection systématique du plateau a été faite après un désherbage général; la zone prospectée s'étend, à l'Est et au Nord, jusqu'à la limite naturelle du plateau (i.e. le ressaut rocheux); au Sud et à l'Ouest, la limite en a été déterminée en considérant l'abaissement du niveau du terrain et la raréfaction du matériel de surface visible ${ }^{7}$. Au total, la zone prospectée mesure, dans son extension maximale, $40 \mathrm{~m}$ (Est-Ouest) sur $25 \mathrm{~m}$ (Nord-Sud), pour une superficie d'environ $680 \mathrm{~m}^{2}$. Pour localiser les trouvailles avec précision, nous avons déterminé des secteurs de ramassage, numérotés de 7001 à 7039, selon une grille aux mailles de $4 \mathrm{~m}$ de côté environ ${ }^{8}$ (fig. 4). En raison de la topographie ${ }^{9}$

7. Le nombre de tessons ramassés, par exemple, dans les secteurs 7028 ou 7035, c'est-à-dire à l'Ouest de la zone prospectée est assez faible : respectivement 34 et 13 tessons; tandis que le secteur 7039, situé sur le long de la limite septentrionale du plateau, non loin de la construction rectangulaire, comprenait 275 tessons; quant au secteur 7006, proche de la façade orientale de la construction, il en comptait 229, alors qu'il est de dimensions réduites.

8. Ainsi, les secteurs $7007(3,71 \mathrm{~m} \times 3,85 \mathrm{~m}), 7011(3,80 \mathrm{~m} \times 4 \mathrm{~m})$ ou $7012(3,80 \mathrm{~m} \times 4 \mathrm{~m})$; les plus réguliers se trouvent vers l'angle Sud-Ouest de la zone prospectée (secteurs 7025, 7026, 7027, 7028, 7032, etc.). Le schéma des secteurs prospectés de la fig. 4 a été restitué en laboratoire à partir des mesures précises indiquées dans le carnet de terrain; il peut donc y avoir des approximations qui ne remettent pas en cause le schéma général.

9. Par exemple les secteurs 7008, 7009, 7010, 7038, 7039, situés en limite de plateau, sont de forme irrégulière. 
et des constructions repérées sur le plateau ${ }^{10}$, certains secteurs sont néanmoins de forme irrégulière. Les comptages effectués peuvent être considérés comme pertinents d'un point de vue statistique, car les secteurs sont de superficie sensiblement équivalente. La céramique des cavités situées en contrebas, en revanche, n’a pas été ramassée de manière systématique. Un matériel abondant y a été collecté plus tard, en 2001, et enregistré sous les numéros 8135 et 8138 . Le matériel recueilli est souvent de grande qualité et de nature assez variée : aussi bien des tessons de céramique commune, des fragments de tuiles, de la céramique fine, des figurines de terre cuite et quelques objets métalliques (des clous notamment). Il n'est jamais stratifié et il s'agit toujours de matériel de surface.

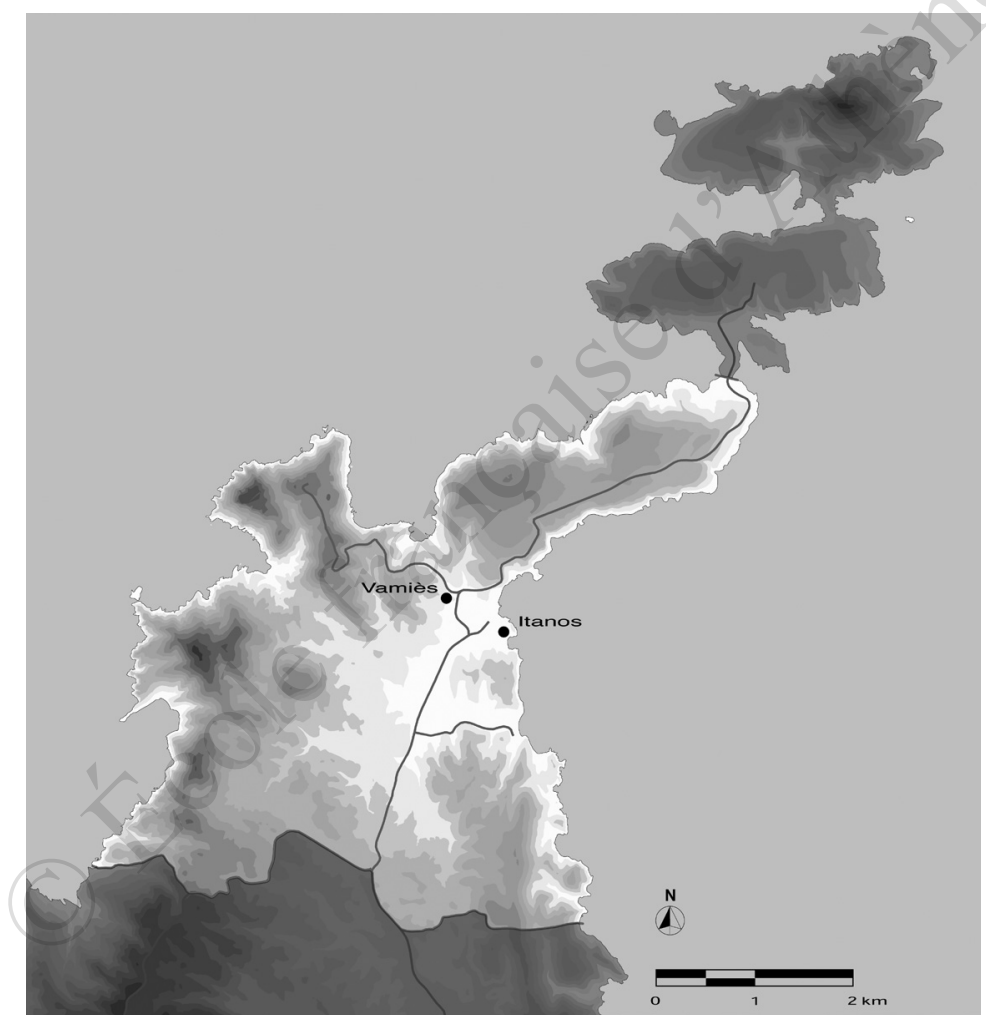

Fig. I - Extension du territoire couvert par la prospection d'Itanos (en clair) et localisation du sanctuaire de Vamiès (carte A. Duplouy).

10. Le secteur 7001, de forme circulaire, est déterminé par les limites d'une aire de battage; 7003 correspond à peu près à la fondation rectangulaire. 


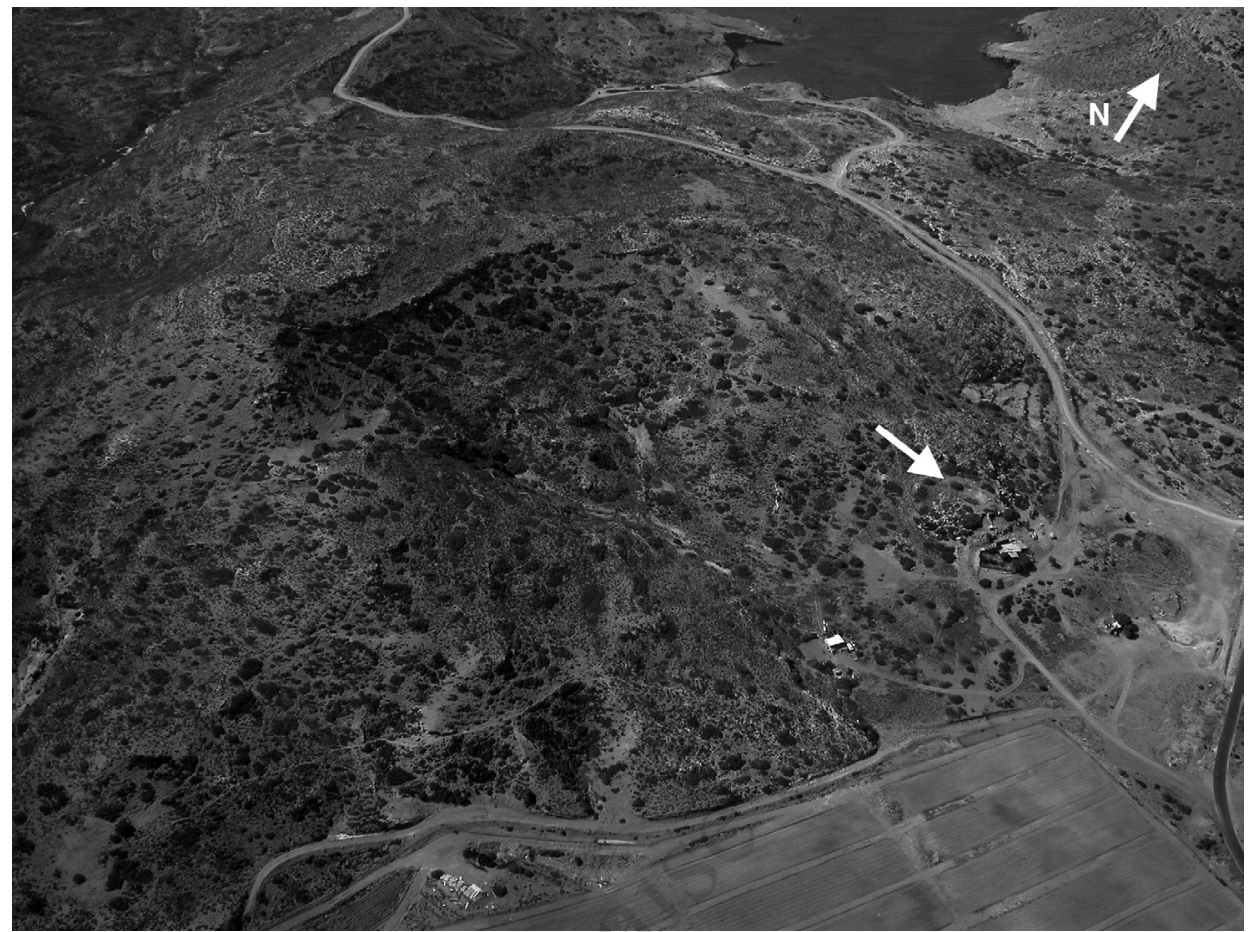

Fig. 2 - Localisation du sanctuaire de Vamiès sur une orthophotographie aérienne de 2003

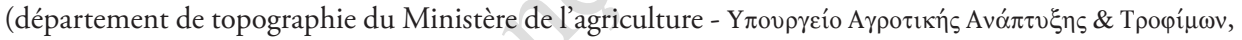
cl. no 700_903).

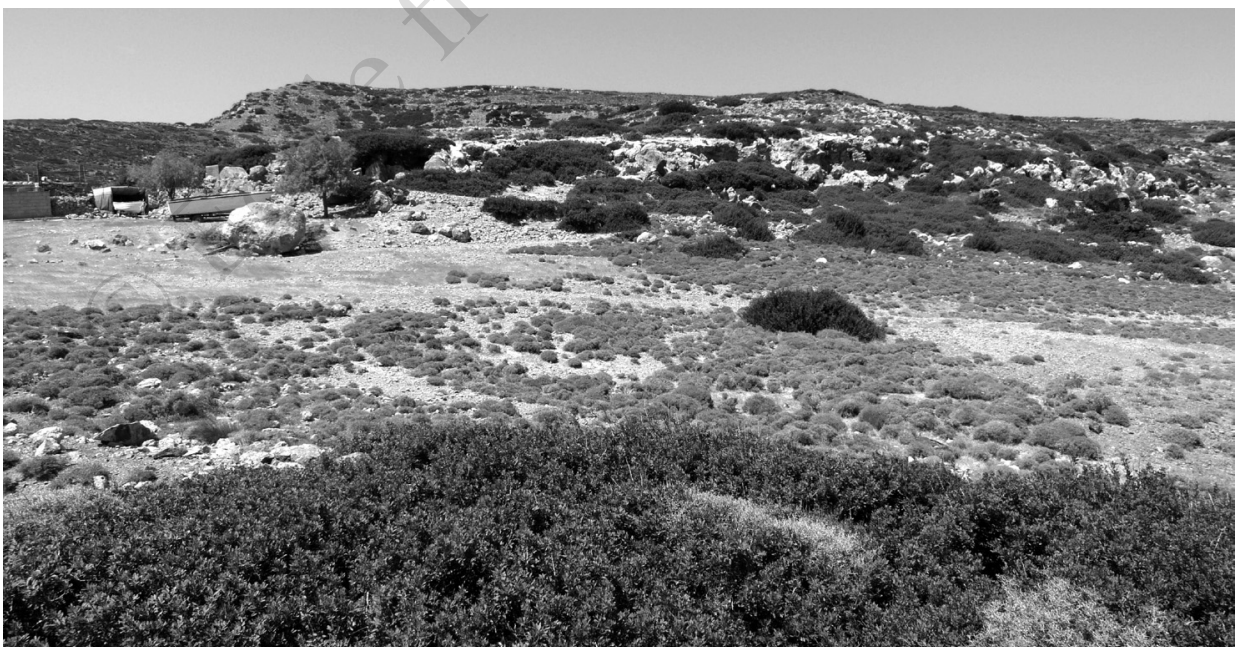

Fig. 3 - Vue générale du plateau de Vamiès depuis le Nord-Est (cl. H. Brun). 


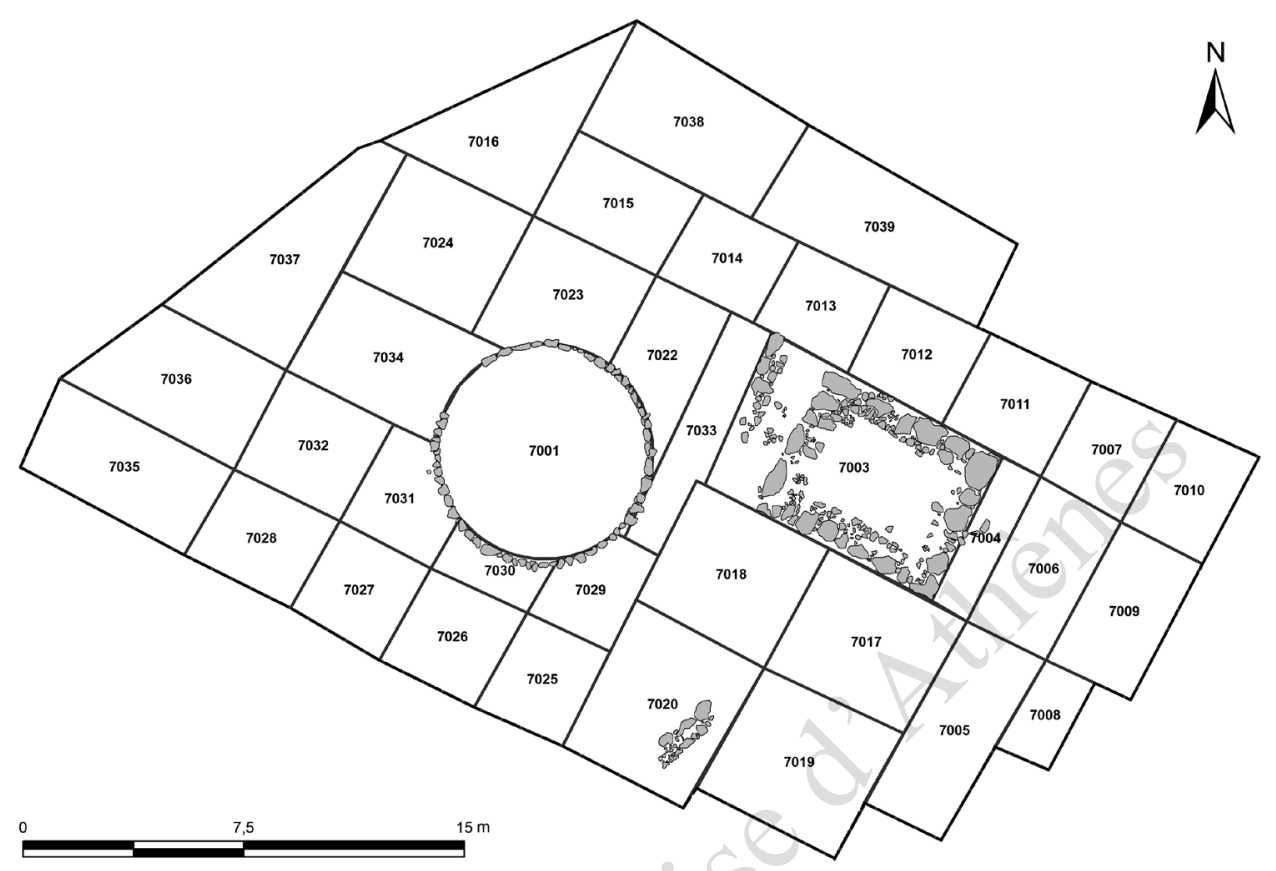

Fig. 4 - Plan topographique du sanctuaire de Vamiès, limites de la prospection de surface et schéma des secteurs de prospection, d'après le carnet de terrain (plan A. Duplouy).

Le nettoyage a également permis de reconnaître au moins un des édifices du sanctuaire. La densité du matériel recueilli dans les différents secteurs prospectés donne une indication sur l'organisation de l'espace sacré et sur son extension, quoique les limites n'en apparaissent pas clairement.

\section{1. LA CONSTRUCTION RECTANGULAIRE}

La seule construction assurément antique conservée sur le plateau est de plan rectangulaire; ses dimensions sont modestes $(6,40 \mathrm{~m} \times 5,20 \mathrm{~m})^{11}$. Elle est orientée Nord-Ouest/ Sud-Est (fig. 4 et 5). Seule la fondation en est intégralement conservée : trois de ses côtés étaient visibles avant notre nettoyage; le mur Nord-Ouest a été mis au jour lors de la campagne de 1996. Les murs de cette fondation sont épais de plus d'1 m, lorsqu'on peut les mesurer, en particulier au Nord, au Sud et à l'Ouest où les deux parements sont bien visibles. Ces murs sont composés de gros blocs de calcaire gris local, mal dégrossis,

11. Dimensions relevées aux murs Nord-Est et Nord-Ouest. 


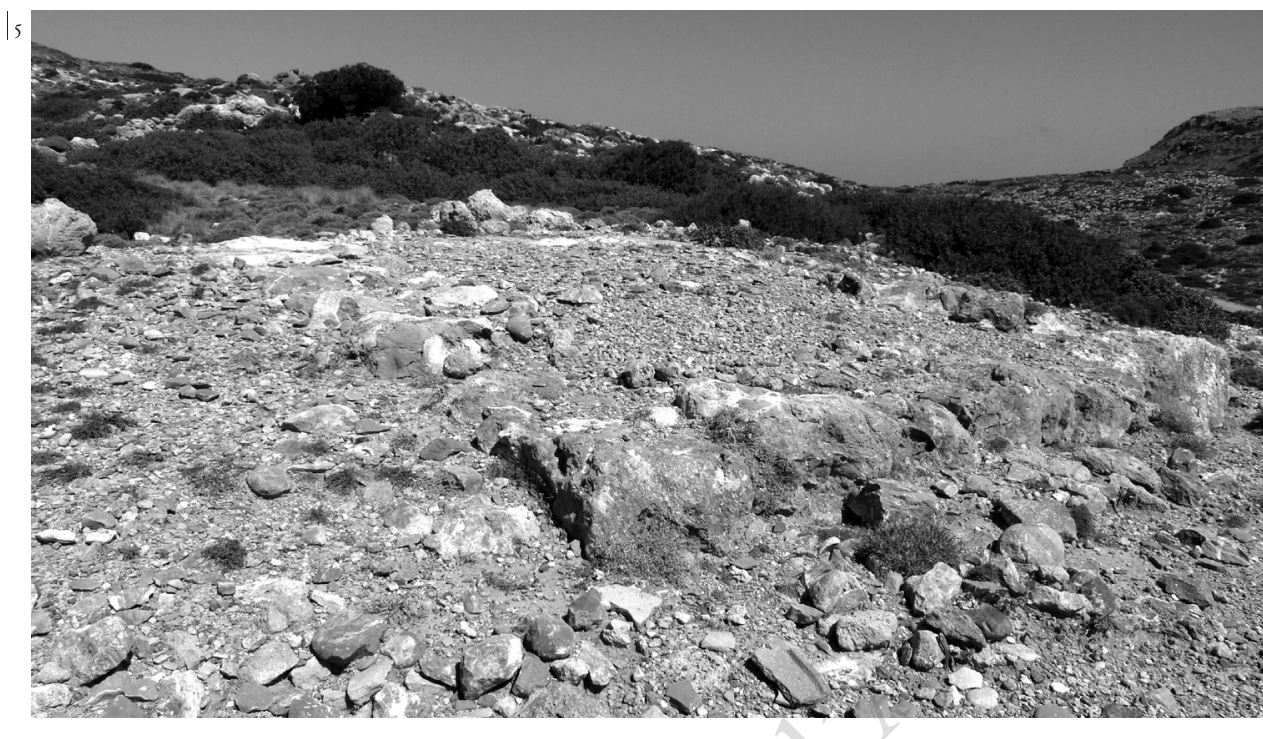

Fig. 5 - Vue de la construction rectangulaire, depuis l'Est (cl. H. Brun).

Fig. 6 - Vue de la fondation du mur NordOuest de la construction rectangulaire, depuis l'Ouest (cl. H. Brun).

assemblés en un appareil fruste (fig. 6). Leur lit d'attente a été aplani avec soin pour recevoir les assises de l'élévation. Cette disposition n'est toutefois observable qu'à l'extrémité occidentale de l'édifice: on peut supposer qu'il manque une assise formant euthyntéria dans la partie orientale où la fondation paraît arasée plus profondément ${ }^{12}$. À l'angle oriental de la construction, on devine l'existence d'une assise en partie enterrée sous le bloc actuellement visible, à moins qu'il ne s'agisse du rocher affleurant à cet endroit, ce que notre nettoyage de surface n'a pas permis de vérifier.

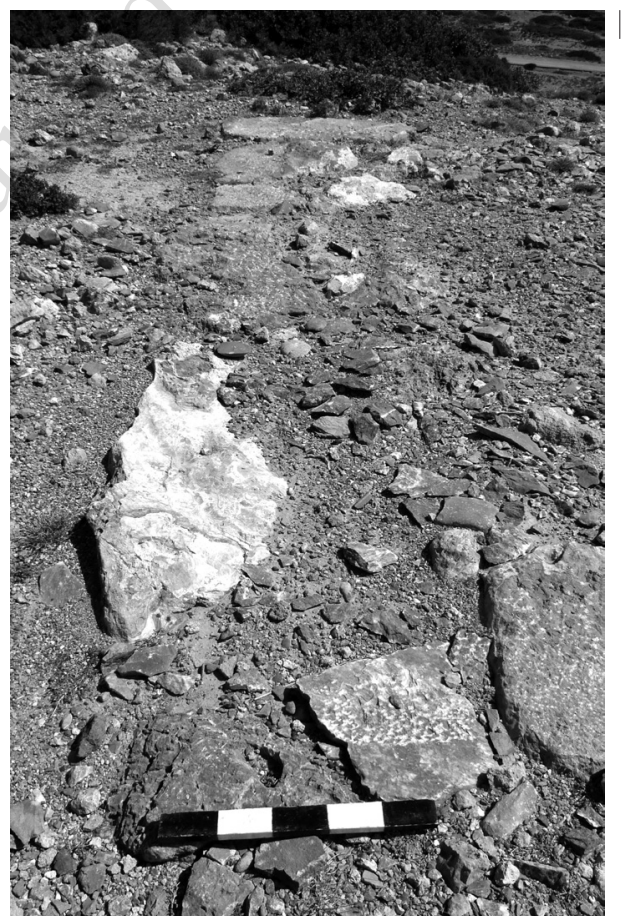

12. On constate une différence d'altitude de près de $45 \mathrm{~cm}$ entre les deux côtés de l'édifice. 
Deux carreaux de calcaire gris - le matériau est identique à celui des fondations - ont été trouvés non loin du mur oriental de la construction et pourraient donc en provenir ${ }^{13}$. Leur restitution à l'édifice est rendue probable par le fait qu'adhèrent encore au lit d'attente de certains blocs de la fondation des restes d'un mortier très dur semblable à celui qui subsiste sur les joints de ces carreaux ${ }^{14}$. Les faces de parement de ces blocs sont piquetées avec assez de soin; ils présentent des joints latéraux obliques. On ne sait pas au juste quelle était leur mise en œuvre dans la construction : tout au plus peut-on assurer qu'ils prenaient place dans un mur à double cours car leur profondeur est irrégulière, sans excéder $15 \mathrm{~cm}$. Peut-être étaient-ils adossés à des moellons et ne constituaient-ils qu'un revêtement extérieur? Par convention nous décrivons les blocs en considérant que le joint oblique est à droite.

Bloc 1 (fig. 7) : Carreau de calcaire gris. Bloc complet. Face de parement décorée d'un piquetage irrégulier; joints latéraux travaillés sur une profondeur de $6 \mathrm{~cm}$ environ puis simplement dégrossis; face postérieure irrégulière. On distingue des traces d'un mortier rosâtre et dur qui adhère aux joints. Le joint latéral droit est oblique. Haut. $26 \mathrm{~cm}$; plus grande long. $37,5 \mathrm{~cm}$; plus petite long. $34 \mathrm{~cm}$; prof. max. $15 \mathrm{~cm}$.

Bloc 2 (fig. 8) : Carreau de calcaire gris. Bloc cassé dans l'angle inférieur droit (convention). Face de parement décorée d'un piquetage irrégulier; joints latéraux travaillés sur une profondeur de $4 \mathrm{~cm}$ environ puis simplement dégrossis; face postérieure irrégulière. On distingue des traces d'un mortier rosâtre et dur qui adhère aux joints. Le joint latéral droit était peut-être oblique, mais comme le bloc est cassé dans un angle, on ne peut en être assuré. Haut. $23 \mathrm{~cm}$; plus grande long. cons. $26 \mathrm{~cm}$; prof. max. $9 \mathrm{~cm}$.

On doit peut-être également restituer à cette construction des tuiles de type corinthien qui ont été trouvées dans sa proximité immédiate, particulièrement nombreuses au Sud, à l'Ouest et au Sud-Est ${ }^{15}$. A. Tsingarida qui en fait l'étude a distingué diverses formes et plusieurs pâtes, sans qu'il faille pour autant en déduire qu'elles appartiennent à des édifices différents ${ }^{16}:$ il peut s'agir de la réfection d'une même toiture ${ }^{17}$.

13. Ils ont été repérés dans le secteur 7004. Ils sont aujourd'hui rangés près de l'angle Nord de l'édifice.

14. Ces traces sont visibles sur le mur Nord-Ouest, en particulier au lit d'attente du deuxième bloc de la fondation, à compter de l'angle Nord.

15. Les tuiles proviennent pour l'essentiel des secteurs 7005, 7017 et 7018. Dans ce dernier notamment, la quasi-totalité de la céramique ramassée (116 fragments) se compose de tuiles dont les fragments étaient surtout concentrés contre le mur Sud-Ouest de la construction et vers son angle Sud. On en a recueilli également beaucoup dans le secteur 7003, dans la partie extérieure de la construction rectangulaire surtout, et dans le secteur 7033, contre son mur Nord-Ouest.

16. Rapport interne (archives de la mission d'Itanos, EFA).

17. La réfection des toitures est attestée par l'épigraphie délienne :ID 144, A, 1. 76 à propos de travaux au Thesmophorion. Il est possible également qu’à la même époque et dans une même phase de construction des tuiles de types divers aient été employées. 


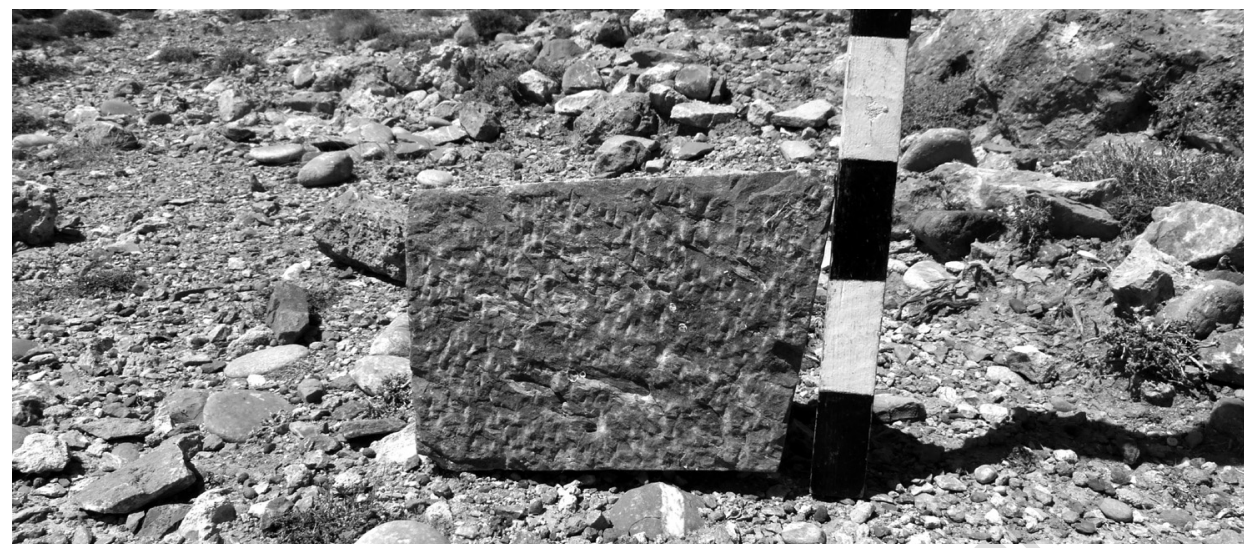

Fig. 7 - Bloc 1 (cl. H. Brun).

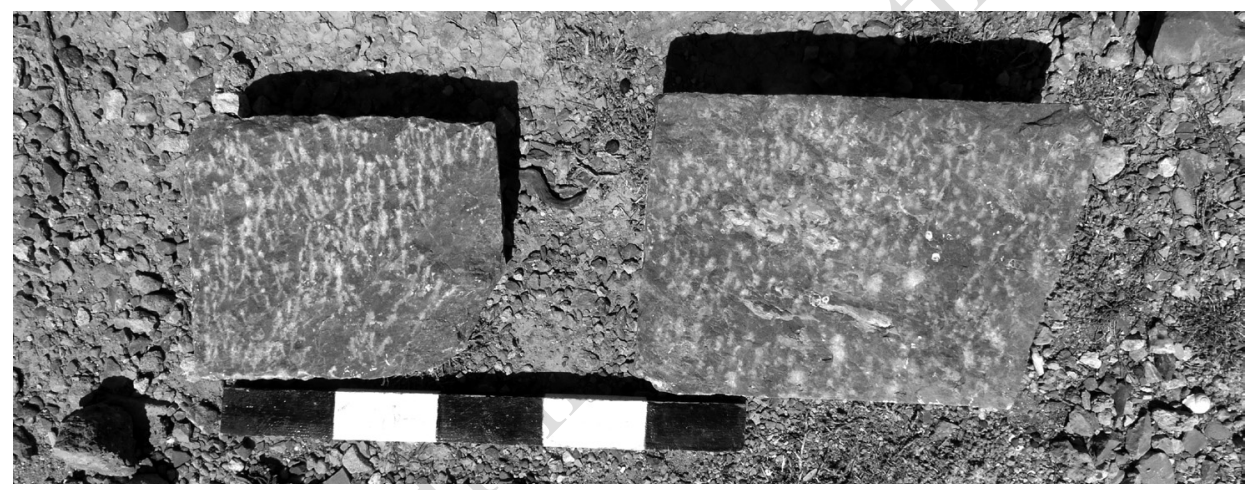

Fig. 8 - Blocs 1 (à droite) et 2 (cl. H. Brun).

L'état de conservation médiocre de cette construction rectangulaire interdit d'en proposer une restitution. L'épaisseur de ses murs peut être estimée à $40 \mathrm{~cm}$, à en juger par les traces de pose sur les fondations, en particulier au Nord-Ouest et au Sud-Ouest où elles sont bien visibles. L'entrée n'est pas conservée; il n'est pas déraisonnable de la situer du côté Sud-Est, mais aucune trace n'en subsiste plus. La construction, probablement couverte, n'avait aucune subdivision interne (aucun mur de refend n'est en effet conservé).

La date de ce modeste édifice ne se laisse pas reconnaître aisément. La céramique trouvée lors de la prospection n'est pas liée aux fondations conservées. K. Sporn évoque la découverte d'une statuette de terre cuite $\mathrm{du} \mathrm{v}^{\mathrm{e}} \mathrm{s}$. dans l'édifice et y voit un indice pour sa datation ${ }^{18}$. Comme les autres, cette statuette ne provient pourtant pas d'un contexte

18. Sporn 2002, p. 36. 
clairement stratifié et il n'est pas possible d'en faire un élément de datation certain. Parmi les statuettes publiées ci-dessous, seules trois proviennent de la construction rectangulaire : 7003.01, 7003.03 et 7003.06; aucune d'elles ne correspond du reste à l'objet évoqué par K. Sporn.

Le peu qui subsiste de l'architecture est par ailleurs très difficile à situer chronologiquement. Les tuiles sont typologiquement trop ordinaires pour être datées aisément, d'autant que ce type de matériel connaît une remarquable stabilité formelle. Un fragment revêtu d'un engobe brun-noir (7017.36) et un autre pourvu d'un engobe noir (7018.36) pourraient néanmoins être archä̈ques. Faut-il en déduire l'existence d'un bâtiment couvert à Vamiès dès cette époque? Là encore, la prudence est de mise, compte-tenu du peu d'informations sur la provenance du matériel recueilli ${ }^{19}$. Si nous avons raison de restituer à cette construction les deux carreaux de calcaire gris décrits plus hauts, nous aurions là, peut-être, un indice précieux pour établir sa date. En effet, leurs joints latéraux obliques et leurs hauteurs variables indiquent que l'appareil du mur était probablement de type trapézoïdal avec des assises pseudo-isodomes, appareil que l'on connait surtout à partir de la fin du Ive s. et à l'époque hellénistique ${ }^{20}$.

Il est tentant de voir dans la construction rectangulaire le temple du sanctuaire; la restitution d'un édifice couvert, ouvrant vers le Sud-Est, s'accorde en effet avec l'architecture attendue d'un naos. La position centrale et isolée de l'édifice paraît également conforter cette hypothèse. D'autres constructions aujourd'hui arasées pouvaient cependant exister dans les environs immédiats et la restitution de l'édifice est de toute façon impossible. Ajoutons enfin que plusieurs fragments d'une même statuette en marbre y ont été découverts.

7003.02 (pied gauche, fig. 9) + 7003.04 (drapé) + 7003.28 (drapé) + 7003.27 (4 fragments)

+ 7003.29 (fragment) (Apothèque de Palaikastro) - Multiples fragments d'une petite statue en marbre (haut. estimée $80 \mathrm{~cm}$ ). Marbre blanc à grain moyen. Long. cons. du pied $5 \mathrm{~cm}$.

Ces fragments de marbre constituent - à peu de choses près ${ }^{21}$ - l'unique témoignage archéologique connu à ce jour à Itanos en matière de sculpture. Seuls quelques éléments de drapé et l'extrémité du pied gauche, posé sur le sol et dépassant du chitôn, sont conservés, Quoique le type paraisse féminin, il est cependant difficile d'exclure tout à fait qu'il s'agisse d'un type masculin. Il est du reste impossible d'en proposer une date. On doit ajouter à ce témoignage la trace d'une autre statuette drapée de grandes

19. Rappelons qu'il s'agit de matériel de surface dont la provenance originelle n'est pas assurée. Sur cette question, voir infra.

20. M.-Chr. Hellmann, L'architecture grecque. I. Les principes de construction (2002), p. 112-113. À Itanos, le mur de terrasse Nord de l'Acropole occidentale a un appareil trapézoïdal, mais les assises sont isodomes. Voir $B C H 119$ (1995), p. 720, fig. 6.

21. Un fragment de jambe de statue en marbre a été trouvé dans le quartier d'habitation : BCH 123 (1999), p. 521 , fig. 7. 


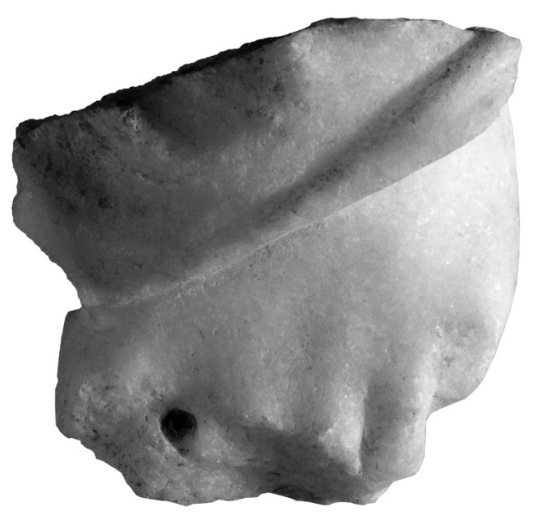

Fig. 9 - Pied en marbre (7003.02) A. Barroche).

rectangulaire comme temple ne sont pas très abondants et aucun n'est absolument déterminant. Nous retiendrons que l'affectation est probable mais non assurée.

\section{2. D'AUtres CONSTRUCtions?}

Sur le plateau où nous avons mené la prospection et dans ses environs se trouvent d'autres aménagements difficiles à associer au sanctuaire. Nous les présentons rapidement.

À $4 \mathrm{~m}$ environ de l'angle Sud-Ouest du temple est conservée une aire de battage d'un diamètre de $7,40 \mathrm{~m}$; il s'agit probablement d'un aménagement tardif ${ }^{22}$, sans lien avec le sanctuaire de Déméter (supra, fig. 4).

Le nettoyage de 1996 a fait apparaître deux tronçons de murs de moellons (supra, fig. 4), assez mal construits et qu'on n'a pas pu suivre sur une grande distance. Le premier, long de $3 \mathrm{~m}$ environ, est bien visible à 1,50 m de l'angle Nord du temple; il suit une direction oblique par rapport aux murs de cet édifice avec lequel il peut n'avoir aucune relation, ni fonctionnelle ni chronologique. Le deuxième se trouve vers le Sud-Ouest à environ 6,50 $\mathrm{m}$ du temple; relativement bien construit, il pourrait s'agir d'un mur antique; il est visible sur une longueur de $2 \mathrm{~m}$ au plus.

À une trentaine de mètres au Nord-Ouest de la zone prospectée se trouvent les vestiges d'une construction rectangulaire arasée ${ }^{23}$, mais qui n'est probablement pas

22. La date en est entièrement inconnue. L'aire peut aussi bien être moderne.

23. Cette construction est répertoriée sous le numéro "Vamiès 66 » dans la base de données en ligne. Aucun tesson n'y a été recueilli. 


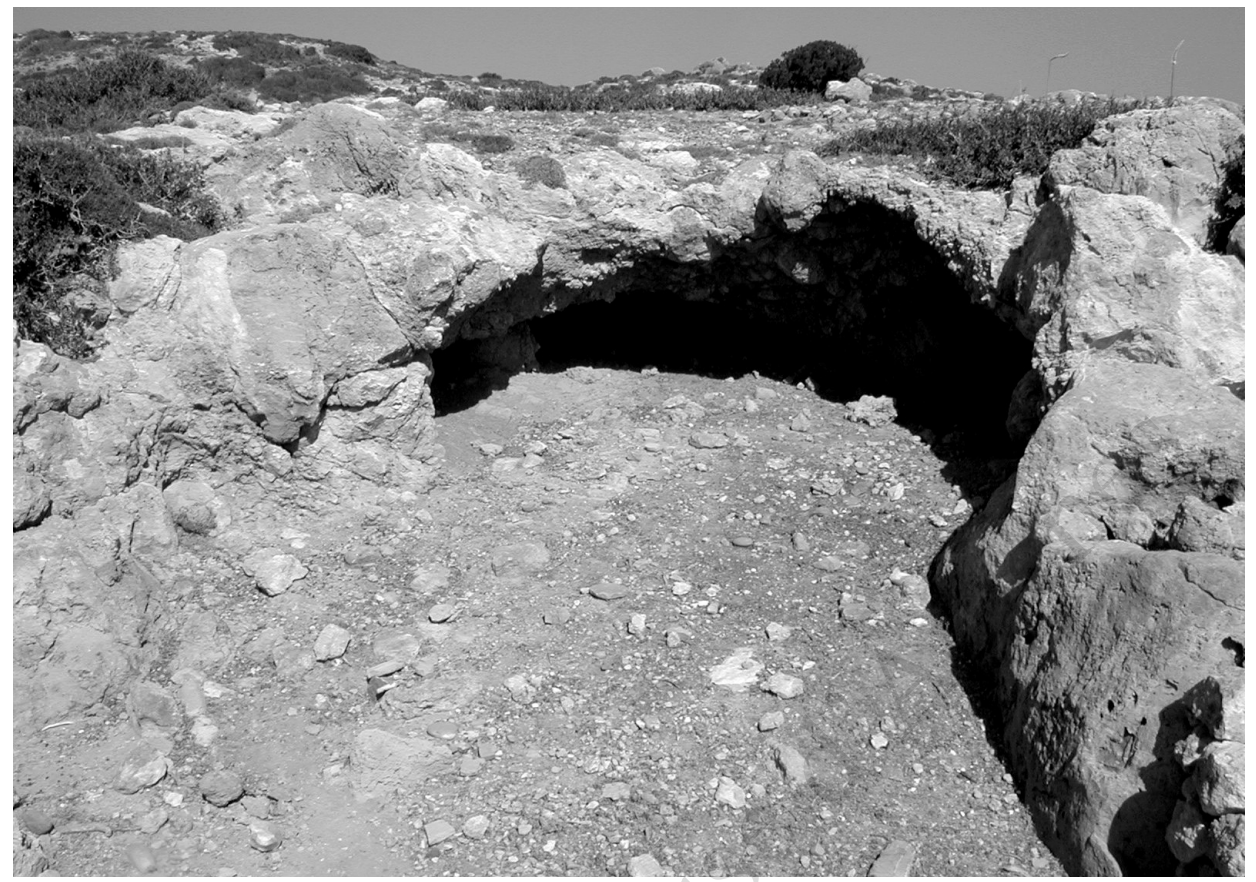

Fig. Io - Cavités creusées dans la roche en contrebas du plateau de Vamiès (cl. A. Duplouy).

liée au sanctuaire lui-même, dont elle est séparée par un abaissement du terrain. Cette construction, à en juger par l'appareil de ses murs, est probablement assez récente.

À environ $30 \mathrm{~m}$ au Nord-Est du temple et en contrebas du plateau du sanctuaire se trouve un puits (ou citerne) circulaire (diam. ext. : 2,80 m; diam. int. : ca 1,30 m) ${ }^{24}$. Il pourrait être antique en raison de la grande quantité de céramique dans ses environs immédiats; on ne sait toutefois s'il entretenait un rapport fonctionnel avec le sanctuaire lui-même. Il a continué d'être employé à l'époque contemporaine : son embouchure a été cimentée et munie d'un couvercle métallique. Le puits est aujourd'hui asséché.

Enfin, on peut mentionner les cavités creusées dans la roche et qui ouvrent vers l'Est et le Nord-Est en contrebas du plateau (fig. Io), dans lesquelles une abondante céramique a été ramassée en 2001 (secteurs 8135 et 8138). K. Sporn inclinait à y reconnaître des mégara ${ }^{25}$, interprétation qui nous semble peu convaincante, car leur examen laisse plutôt penser qu'elles résultent, nous l'avons dit plus haut, d'un effondrement naturel dont la

24. Il n'est pas répertorié comme structure dans la base de données de la prospection, mais figure sur le plan général.

25. SPORn 2002, p. 37. 
date est impossible à préciser. La céramique présente en assez grande quantité dans ces " grottes ", et en contrebas du plateau d'une manière générale, a sans doute coulé depuis la partie supérieure où se trouve le sanctuaire; on ne peut donc inférer de la présence de matériel dans ces cavités qu'elles avaient partie liée avec des célébrations cultuelles. Certaines ont fait l'objet d'aménagements contemporains : l'une d'elles, du côté Nord, est fermée par une porte pour servir de réserve; à l'Est, d'autres sont précédées d'une sorte d'enclos grossièrement construit. Ces travaux sont probablement imputables aux bergers qui exploitent encore aujourd'hui le site de Vamiès.

Dans l'état actuel de l'étude, il est difficile de préciser l'organisation du sanctuaire de Vamiès. Les autres constructions du plateau ou des environs immédiats paraissent appartenir à des aménagements récents; beaucoup sont impossibles à dater et leur affectation même est problématique. Si le sanctuaire comportait d'autres constructions que l'édifice rectangulaire, possible temple, il n'en reste nulle trace claire aujourd'hui. Rappelons cependant que le plateau n'a pas été fouillé, mais simplement désherbé.

\section{3. EXTENSION DU SANCTUAIRE DE VAMiÈs}

Nous connaissons en somme assez mal les aménagements du sanctuaire de Vamiès et il est impossible d'en reconnaître précisément l'organisation architecturale. Toutefois, le décompte du matériel ramassé dans les différents secteurs peut donner quelques indices sur ses limites et sur son organisation interne. Le tableau suivant permet de calculer les densités de matériel récolté dans chaque secteur et de les représenter sur le plan topographique des secteurs de prospection (fig. II).

\begin{tabular}{|c|c|c|c|}
\hline Secteur & Surface $\left(\mathbf{m}^{2}\right)$ & Nombre de tessons & Densité (tessons/m²) \\
\hline \hline 7001 & 42 & 49 & 1,17 \\
\hline 7003 & 49 & 26 & 0,53 \\
\hline 7004 & 8 & 15 & 1,88 \\
\hline 7005 & 21 & 411 & 19,57 \\
\hline 7006 & 17 & 229 & 13,47 \\
\hline 7007 & 12 & 319 & 26,58 \\
\hline 7008 & 6 & 0 & 0 \\
\hline 7009 & 17 & 172 & 10,12 \\
\hline 7010 & 12 & 890 & 74,17 \\
\hline 7011 & 14 & 135 & 9,64 \\
\hline
\end{tabular}




\begin{tabular}{|c|c|c|c|}
\hline Secteur & Surface $\left(\mathbf{m}^{2}\right)$ & Nombre de tessons & Densité (tessons/m²) \\
\hline 7012 & 13 & 114 & 8,77 \\
\hline 7013 & 11 & 35 & 3,18 \\
\hline 7014 & 12 & 87 & 7,25 \\
\hline 7015 & 15 & 77 & 5,13 \\
\hline 7016 & 22 & 74 & 3,36 \\
\hline 7017 & 24 & 453 & 18,88 \\
\hline 7018 & 23 & 116 & $5,04 \bigcirc$ \\
\hline 7019 & 25 & 375 & $15 \bigcirc$ \\
\hline 7020 & 26 & 12 & 0,46 \\
\hline 7022 & 13 & 39 & 3 \\
\hline 7023 & 18 & 37 & 2,06 \\
\hline 7024 & 22 & 65 & 2,95 \\
\hline 7025 & 12 & $102 \circlearrowleft$ & 8,50 \\
\hline 7026 & 13 & 31 & 2,38 \\
\hline 7027 & 12 & 44 & 3,67 \\
\hline 7028 & 14 & 34 & 2,43 \\
\hline 7029 & 10 & 70 & 7 \\
\hline 7030 & $6 e^{\circ}$ & 25 & 4,17 \\
\hline 7031 & 11 & 22 & 2 \\
\hline 7032 & 15 & 42 & 2,80 \\
\hline 7033 & 13 & 61 & 4,69 \\
\hline 7034 & 22 & 54 & 2,45 \\
\hline 7035 & 22 & 13 & 0,59 \\
\hline 7036 & 22 & 31 & 1,41 \\
\hline 7037 & 25 & 68 & 2,72 \\
\hline 7038 & 27 & 79 & 2,93 \\
\hline 7039 & 29 & 275 & 9,48 \\
\hline 8135 & $\mathrm{NC}$ & 52 & - \\
\hline 8138 & $\mathrm{NC}$ & 25 & - \\
\hline
\end{tabular}

Tableau I : Densité de matériel par secteur du plateau de Vamiès 


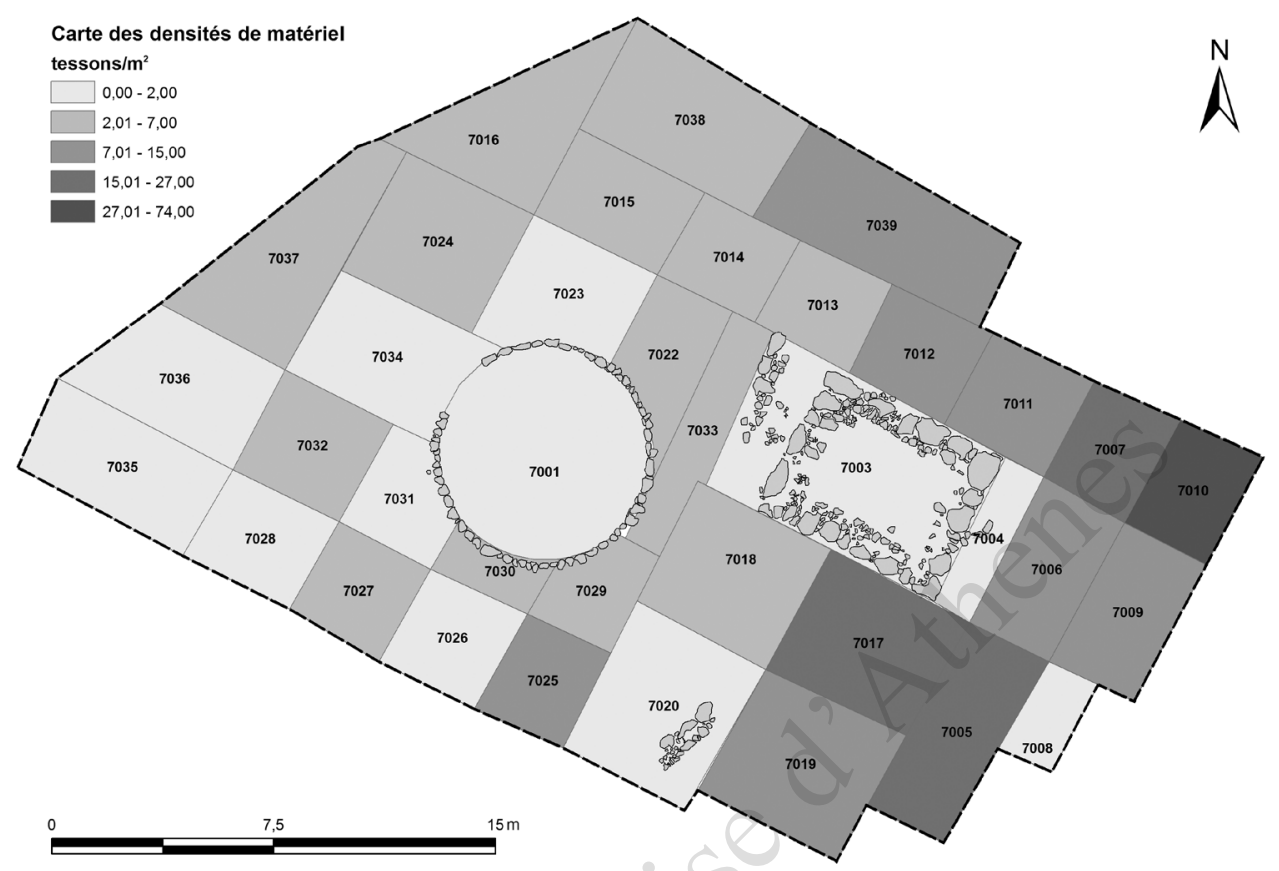

Fig. II — Carte des densités de matériel (A. Duplouy).

Pour interpréter ces résultats, il faut, bien entendu, tenir compte de la configuration naturelle du terrain, qui accuse une assez forte pente d'Ouest en Est ${ }^{26}$ et du Nord vers le $\mathrm{Sud}^{27}$, ce qui, ajouté aux phénomènes de ruissellement nettement visibles, a pu avoir pour effet de favoriser les concentrations de matériel en certains points du plateau, sans lien nécessaire avec le lieu où il était originellement conservé. Ces précautions prises, le matériel ramassé était notablement plus abondant à l'Est et au Sud du temple qu'à l'Ouest et au Nord: il était surtout concentré autour de la construction elle-même, tandis qu'à mesure qu'on s'en éloigne vers l'Ouest, la concentration des tessons dans chaque secteur diminue rapidement.

Pour résumer, et avec toute la prudence qui s’impose, il semble bien que le matériel était entreposé non loin du temple, plus exactement même au Sud-Est de celui-ci, face à ce qui en serait l'entrée; peut-être même une partie se trouvait-elle rangée dans l'édifice lui-même qui pouvait servir de lieu de dépôt. Une partie également de ce matériel de surface peut provenir de fosses où il aurait été mis au rebut avant d'être remis au jour par l'érosion due aux eaux de ruissellement. Dans tous les cas, matériel stocké et en usage ou

26. Altitude à l'Ouest : 34,39 m; à l'Est : 32,35 m.

27. Altitude au Nord : $34,83 \mathrm{~m}$; au Sud : 33,22 m. 
matériel usagé enfoui dans des favissae, il devait se trouver dans la proximité immédiate de la construction rectangulaire. La zone prospectée doit donc correspondre plus ou moins à l'extension maximale du sanctuaire de Vamiès, même si aucune limite construite n'a été repérée. En revanche, comme nous l'avons dit, le plateau devait s'étendre davantage vers le Nord-Est et l'Est avant que le front rocheux ne s'effondre dans la pente.

\section{LA PETITE PLASTIQUE DE TERRE CUITE}

Le nettoyage de surface et la prospection menée en 1996 (avec des compléments en 2001) ont livré une petite collection de terres cuites s'échelonnant du vir au Ir s. av. J.-C. Bien que restreint, l'échantillon de figurines collecté offre l'occasion de diverses comparaisons avec d'autres sanctuaires, ainsi qu'avec plusieurs pièces de musée de provenance inconnue ou peu assurée. Ce n'est d'ailleurs pas là le moindre intérêt du sanctuaire de Vamiès que d'apporter des indications nouvelles sur la provenance et la distribution de certains types. Outre le sanctuaire de Déméter à Cnossos, avec lequel il partage de nombreuses caractéristiques, cet ensemble trouve des parallèles dans plusieurs sanctuaires de Crète orientale, en particulier pour les types archaïques :

- le dépôt d'Olonte, découvert en 1960 par N. Platon sur l'isthme rattachant la presqu' île de Spinalonga à la terre ferme ${ }^{28}$. Cet ensemble votif, dont le matériel s'étend de la fin du viI ${ }^{e}$ au ve s., contenait plus de mille terres cuites (de Corinthe, d'Athènes et de Grèce de l'Est), des vases à parfum protocorinthiens et une abondante céramique attique à figures noires. Bien qu'aucune structure architecturale n'ait été découverte, il indique l'emplacement d'un petit sanctuaire de plein air vraisemblablement associé à Déméter. Les terres cuites sont en partie exposées au musée d'Agios Nikolaos, mais demeurent pour l'essentiel inédites ${ }^{29}$.

- le dépôt de Sitia, découvert en 1977 par N. Papadakis lors de travaux de construction en ville ${ }^{30}$. L'ensemble du dépôt a livré environ 900 figurines en terre cuite des époques géométrique et orientalisante. Rien n’est connu du contexte

28. N. Platon, $A D 16$ (1960), p. 259-260; CretChron 14 (1960), p. 512 ; BCH 85 (1961), p. 869-871. Voir

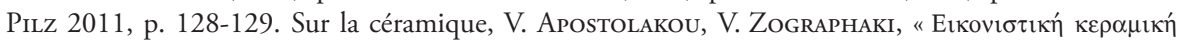

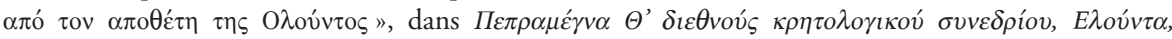

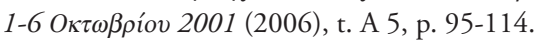

29. Voir néanmoins C. Davaras, Musée de Hagios Nicolaos (1983), fig. 81-84. Elles ont été présentées lors du congrès crétologique de Chania en 2006; voir V. Apostolakou, V. Zographaki, «Eı $\delta \dot{\lambda} \lambda_{1} \alpha \alpha \pi$ $\alpha$ to

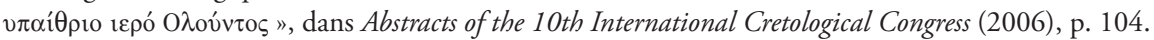

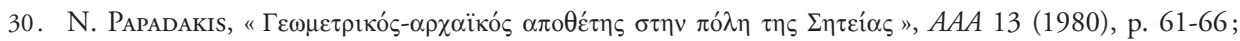

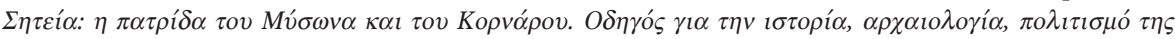
(1989), p. 121-122. Voir Prent 2005, p. 300-301 (B. 41); Pilz 2011, p. 112-113. 
exact de découverte. Une sélection des terres cuites est exposée aux musées d'Agios Nikolaos et de Sitia; elles sont pour l'essentiel inédites ${ }^{31}$.

- le dépôt de Vavelloi, situé à environ 1,2 km au Sud de l'acropole A de Praisos, fouillé par Halbherr en 1894 puis par Bosanquet en 1901, mais largement pillé lors de la révolution de 1896, a livré plusieurs centaines de terres cuites archaïques, classiques et hellénistiques. Si un lot important a rejoint le musée d'Héraklion, les découvertes sont en fait dispersées à travers de multiples collections, publiques et privées, en Europe et aux États-Unis; il n'en existe malheureusement aucune publication d'ensemble ${ }^{32}$. Il s'agit ici d'un petit sanctuaire de source, sans trace d'autel ni de temple, peut-être lié au culte de Déméter. Le site fut retrouvé en 1998 au cours du survey de Praisos et a livré un lot de terres cuites supplémentaires, ainsi que des vases miniatures et des lampes à becs multiples ${ }^{33}$.

- le dépôt de Roussa Ekklesia, dans l'arrière-pays de Sitia, fouillé par N. Platon en 1954, puis par N. Papadakis en 1982 et récemment publié par Br. Erickson ${ }^{34}$. Associé à un petit sanctuaire rural de plein air, proche d'une source, sans aucune structure architecturale apparente, cet ensemble de terres cuites archaïques et classiques provient de la fouille de plusieurs bothroi, dans lesquels furent également retrouvés des coupes à boire, des kernoi et des lampes s'étendant jusqu'à 150 av. J.-C. environ. Erickson a proposé d'y voir le lieu d'un culte consacré aux nymphes.

Dans le catalogue qui suit, la petite plastique est classée par type et présentée chronologiquement. Seules les pièces les plus significatives sont illustrées. Les numéros sont ceux qui leur ont été attribués lors de la prospection : ils correspondent aux différents secteurs de ramassage, tels que décrits ci-dessus, et donnent ainsi une répartition spatiale du matériel, qui n'offre malheureusement guère d'indications exploitables sur un éventuel lieu privilégié de consécration ni même de stockage des terres cuites. Outre la découverte de quel-

31. Voir néanmoins C. Davaras (n. 29), fig. 79-80. Elles ont été présentées lors du colloque du DAI sur la Crète

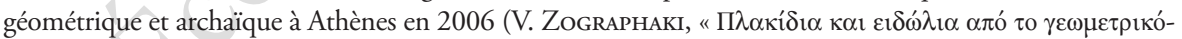

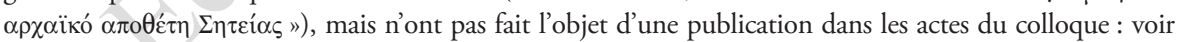
W.-D. Niemeier, O. Pilz, I. Kaiser (éds), Kreta in der geometrischen und archaischen Zeit: Akten des Internationalen Kolloquiums am Deutschen Archäologischen Institut, Abteilung Athen, 27.-29. Januar 2006 (2013).

32. F. Halbherr, "Cretan Expedition XVI. Report on the Researches at Praesos ", AJA 5 (1901), p. 371-392, en particulier 384-392; E. S. Forster, "The Terra-Cottas", BSA 8 (1901-1902), p. 271-281, en particulier p. 280-281; id., "Terracotta Plaques from Praesos, East Crete ", BSA 11 (1904-1905), p. 243-257; Prent 2005, p. 306-308 (B. 46); Pilz 2011, p. 106-108; O. Pilz, " Die Kulte von Praisos in der spätgeometrischen und archaischen Zeit », dans W.-D. Niemeier, O. Pilz et I. Kaiser (éds) (supra), p. 367-377, en particulier p. 370-372.

33. AR 45 (1998-1999), p. 122.

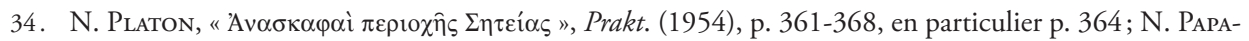
Dakis, AD 37 (1982), p. 389; Erickson 2009. Voir Prent 2005, p. 301-302 (B. 42); Pilz 2011, p. 113-118. 
ques pièces ou fragments à l'intérieur de la structure rectangulaire (7003), probable naos, et dans l'aire de battage (7001), qui a pu retenir une couche superficielle plus importante, les figurines en terre cuite se concentrent, comme le reste du matériel, à l'Est et au Sud de la structure (7004, 7007, 7009, 7010 et 7017), soit devant l'entrée probable de celle-ci mais aussi dans le secteur le plus bas d'un plateau soumis à des phénomènes de ruissellement.

\section{1. TyPes DÉdAliQUeS}

Trois exemplaires appartenant à des types dédaliques caractéristiques ont été découverts lors de la prospection du sanctuaire de Vamiès.

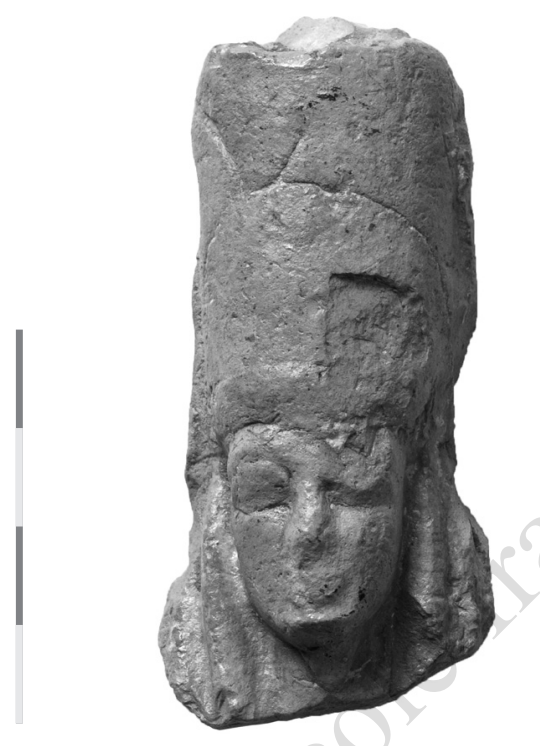

Fig. I2 - Dame au polos (7001.47) (cl. A. Barroche).

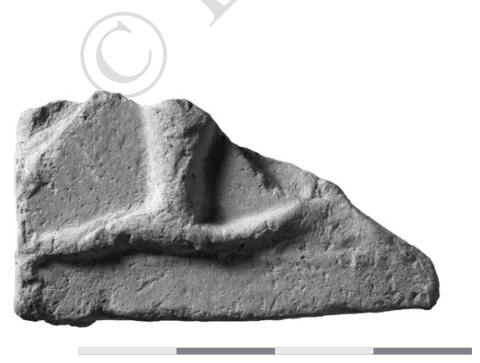

Fig. 13 - Plaquette moulée (7001.35) (cl. A. Barroche).
7001.47 (Musée de Sitia, 10922 Vitrine, fig. I2) - Tête féminine coiffée d'un haut polos cylindrique, brisée au cou. Un éclat de surface endommage en partie le polos. Le visage est trapézoïdal plutôt que triangulaire et tend à s'arrondir au niveau du menton, non sans rapport avec ce que R. J. H. Jenkins appelait le "dédalique moyen ». La coiffure se compose, de part et d'autre du visage, de deux parotides lisses. Pâte beige rosée assez fine, avec de petites inclusions blanches et brunes; la pièce a été restaurée et vernie [10YR 6/8, avec vernis], ce qui rend l'observation difficile. Haut. cons. $7,6 \mathrm{~cm}$. Ép. 1,5 à $2 \mathrm{~cm}$. Date : deuxième quart du viI ${ }^{\mathrm{s}} \mathrm{s}$.

Ce type appartient à la série bien représentée en Crète au viI $s$. des plaquettes moulées à l'avers représentant une jeune femme debout, nue ou habillée. Il n'est pas possible de déterminer si notre exemplaire était nu ou vêtu.

7001.35 (Apothèque de Palaikastro, fig. 13) - Plaquette de terre cuite moulée, brisée : seul l'angle inférieur gauche est conservé. Le motif estampé est fait d'une "ligne ondulée " d'épaisseur variable, parallèle à l'un des bords de la plaquette; perpendiculairement à celle-ci, un «boudin " s'élargit légèrement à mesure que l'on s'écarte de la "ligne ondulée ». La pièce 
est brisée obliquement. Pâte jaune orangé [7.5YR 7/6], fine, dure avec de petites inclusions blanches et brunes. Dim. cons. $4,5 \mathrm{~cm}$ $\times 2,5 \mathrm{~cm}$; ép. $0,6 \mathrm{~cm}$. Date : troisième quart du VII $s$.

Face à un fragment aussi indigent, toute interprétation doit rester prudente. Il est toutefois vraisemblable qu'il faille y voir l'image d'un personnage en tunique courte dirigé vers la gauche, selon un type particulièrement fréquent dans les sanctuaires de Praisos ("Fourth Terrace » et Vavelloi) et de son territoire (Roussa Ekklesia, Sitia, Stou Koukou to Kephali, Prophitis Ilias). Connu par quelques exemplaires anciennement publiés, le type a été restitué par Br. Erickson à partir de divers fragments du dépôt de Roussa Ekklesia ${ }^{35}$. Il s'agit de plaquettes larges de 4 à $5 \mathrm{~cm}$ et hautes d'une quinzaine. Nous aurions à Vamiès la partie inférieure de l'une de ces plaquettes: une jambe brisée à mi-mollet, ainsi que les deux pieds posés l'un devant l'autre (fig. I4). La cassure oblique, qui a arraché tout l'épiderme de la plaquette sur la partie droite, a fait disparaître l'autre jambe ainsi que le talon du pied de droite. La restitution doit bien sûr être évaluée à l'aune de la modestie du fragment conservé.

7017.02 (Musée de Sitia, 10240 Vitrine, fig. 15) - Tête féminine moulée pleine; l'arrière plat n'est pas travaillé. Le personnage portait un voile, qui couvrait les cheveux. Un trou a été ménagé dans la masse à

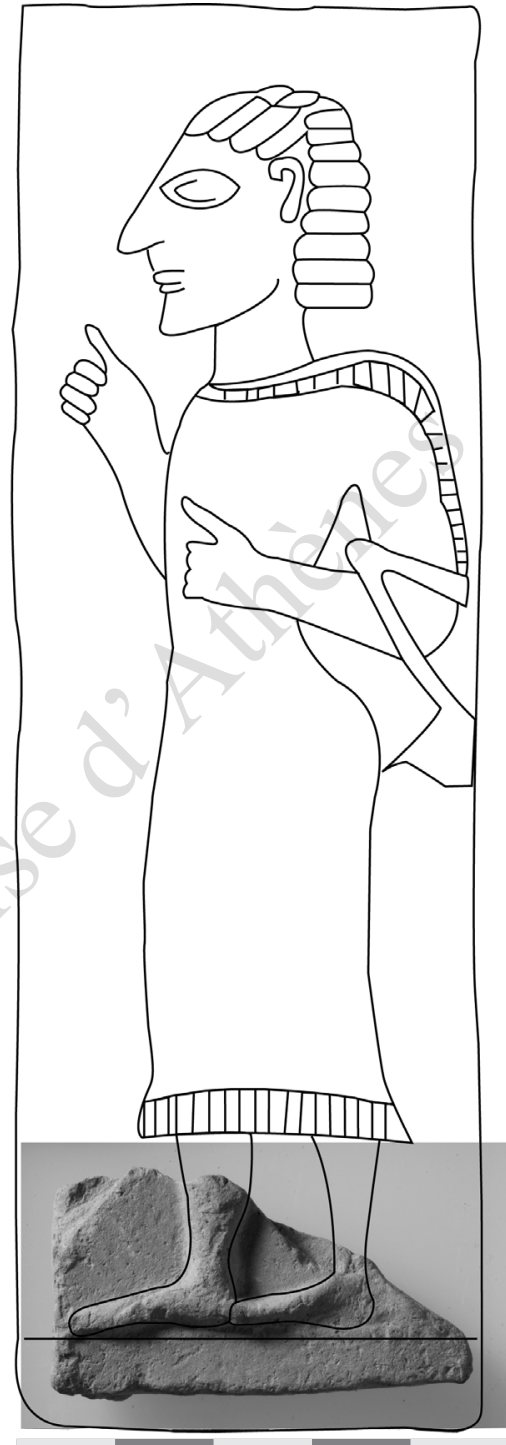

Fig. 14 - Restitution de 7001.35 au sein du schéma (fig. 11) publié par Br. Erickson (dessin A. Zambon).

35. F. Halbherr (n. 32), p. 389, pl. XII, fig. 1-2 ; E. S. Forster, BSA 8 (1901-1902), p. 280 ; E. H. Dohan, "Archaic Cretan Terracottas in America», MMS 3 (1931), p. 215-216, fig. 10; J. WhitLey et al., BSA 94 (1999), p. 251 ; ERICKson 2009, p. 365-370, 380-382, fig. 11. Il s'agit du type IV/3 (640-620) de Pilz 2011, p. 229-232. 
la base du cou. La pièce a été vernie par les restaurateurs du musée. Argile dure, rouge sombre [10R 5/6, avec vernis], avec de nombreuses inclusions assez grosses donnant un aspect de surface rugueux. Couverte blanche sur le voile [10YR $8 / 2$, avec vernis], ainsi que sur tout le revers et la base de la tête. Haut. cons. $8,4 \mathrm{~cm}$. Date : seconde moitié du vi's.

La tête a été trempée dans un bain d'engobe de manière légèrement dissymétrique, le côté gauche étant engobé davantage vers l'avers. La base de la tête étant

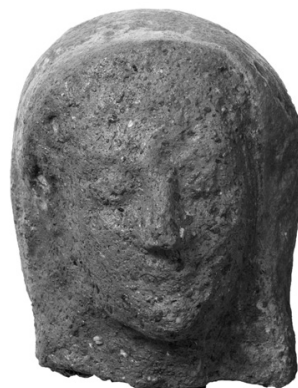

Fig. 15 - Tête moulée pleine (7017.02) (cl. A. Barroche).

pourvue de cette couverte, la terre cuite est entière; il ne s'agit donc pas d'une tête brisée et séparée de son corps. Le trou ménagé à la base devait permettre de ficher la tête sur un tenon, afin de l'insérer dans un corps (fig. I6). Semblables têtes à encastrer dans des corps cylindriques sont bien représentées dans le dépôt archaïque de Sitia, dont
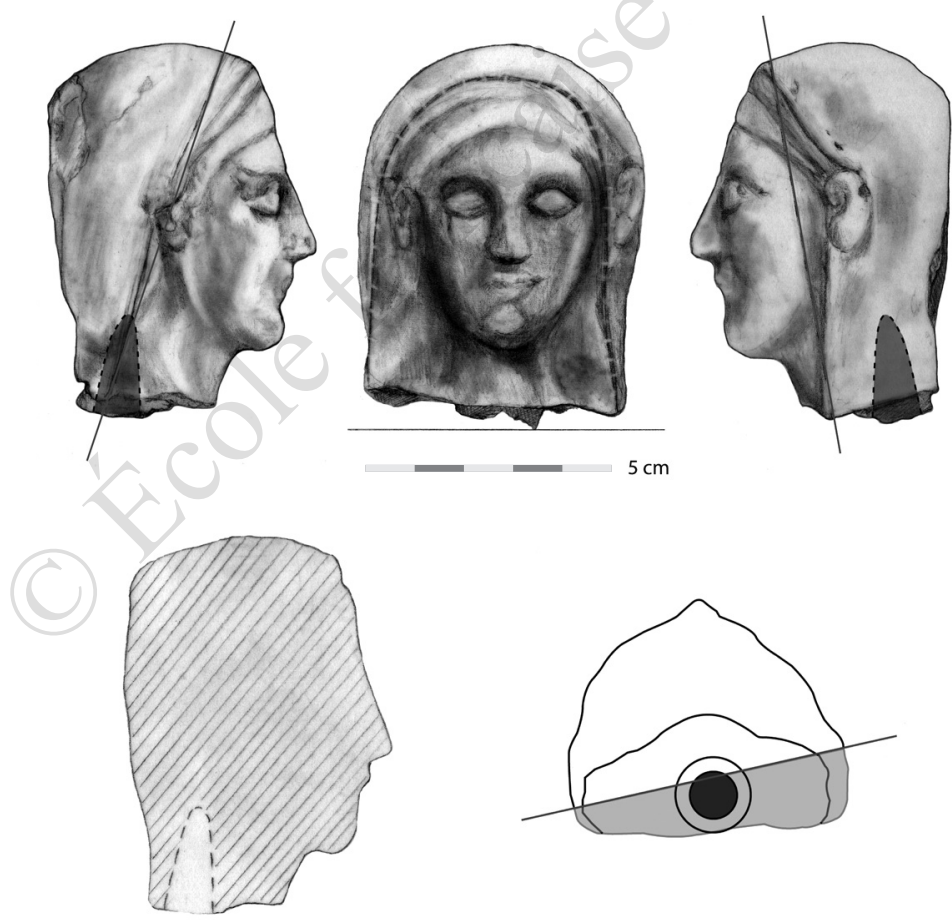

Fig. 16 - Tête moulée pleine (7017.02) (dessin A. Zambon). 
quelques exemplaires ont été publiés ${ }^{36}$. Le plus souvent, le tenon d'encastrement fait partie de la tête, mais il semble parfois avoir été fabriqué à part. Bien que le type ne soit pas attesté dans les dépôts bien documentés de Vavelloi et de Roussa Ekklesia, il s'agit vraisemblablement, ici aussi, d'un type de la plastique de Crète de l'Est.

\section{2. Protomés fÉminines ARChaÏQUeS}

Plusieurs protomés féminines archaïques ont été découvertes lors de la prospection du sanctuaire de Vamiès.

7017.22 (Musée de Sitia, 10239 Vitrine, fig. 17) - Protomé féminine en forme de buste, percée d'un orifice de suspension sur la partie supérieure de la tête. La tête, coiffée d'un voile couvrant la chevelure, est prolongée vers le bas par un plastron semi-circulaire figurant le départ du buste. La pièce a été entièrement vernie par les restaurateurs du musée. Pâte jaune rougeâtre [10YR $6 / 8$, avec vernis], avec de petites inclusions blanches. Trace de couverte blanche. Haut. $7,8 \mathrm{~cm}$. Date : fin $\mathrm{VI}^{\mathrm{e}} \mathrm{s}$.

7010.39 (Musée de Sitia, 10933) - Cinq fragments de protomé. Les fragments $\beta$ et $\delta$ collent et forment la partie supérieure gauche du visage: le départ du voile et l'esquisse de l'œil. L'arrière a été lissé et confirme l'identification comme protomé. Trop peu en est toutefois conservé pour

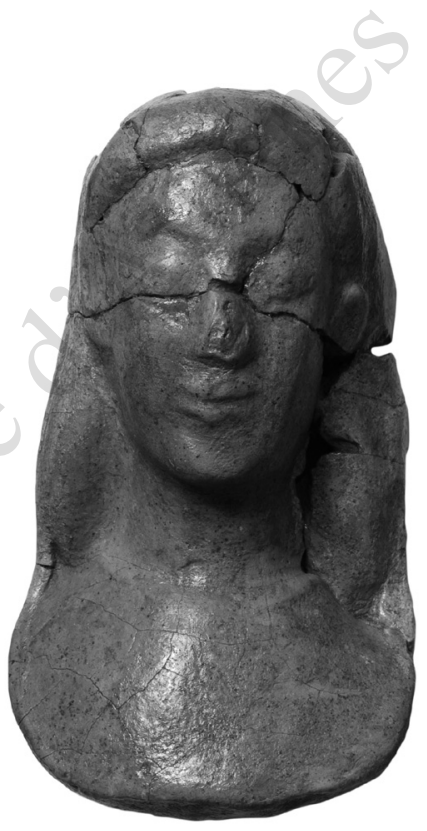

Fig. 17 - Protomé (7017.22) (cl. A. Barroche). proposer une origine ou une datation.

Pâte très contrastée entre l'extérieur, gris jaune [10YR 7/3 à 7/4], et l'intérieur, gris foncé [10YR 4/1]; la protomé a été peu (ou mal) cuite. Pâte micacée très dure à l'intérieur, tendre à l'extérieur. Haut. cons. 4,6 cm.

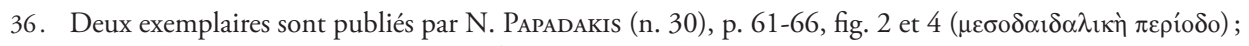
voir également C. Davaras (n. 29), fig. 79. De nombreux autres sont exposés aux musées de Sitia et d'Agios Nikolaos. Trois têtes, conservées dans des collections privées suisses, viennent vraisemblablement de Crète de l'Est, voir P. Blome, Die figurliche Bildwelt Kretas in der geometrischen und früharchaischen Periode (1982), p. 32-33 (reifdädalische), pl. 14, 2-4. 
7007.01 (Musée de Sitia, 10927) — Fragment de protomé. L’arrière a été lissé et confirme l'identification comme protomé. Il est difficile de déterminer la partie conservée : un morceau du "plastron " latéral (?) et le début du relief du visage (cheveux? oreille?). Pâte beige rose micacée [7.5YR 6/4], dure, avec de gros dégraissants noirs. Dim. cons. $7 \times 6,4 \mathrm{~cm}$.

Notons au passage que la présence d'un trou de suspension sur 7017.22, lié à la typologie de la protomé, donne une indication précieuse sur la disposition des offrandes dans le sanctuaire : comme on l'a fait pour les plaquettes de Penteskouphia, on pourrait imaginer que pareille protomé était suspendue aux buissons.

\section{3. TYPES FÉMININS DE LA FIN DE L'ARCHAÏSME ET DU CLASSICISME}

Les types féminins de la fin de l'archaïsme et du classicisme découverts lors de la prospection du sanctuaire de Vamiès marquent, comme nous le verrons, une diversification typologique et stylistique, autant qu'ils permettent de conforter, grâce au type de l'hydrophore, l'identification de la divinité vénérée à Vamiès.

7001.46 (Musée de Sitia, 10921, fig. 18)

— Bas d'un visage rond. L'arrière de la tête non lissé et particulièrement irrégulier, ainsi que l'épaisseur variable de la croûte d'argile tendent à indiquer qu'il ne s'agit pas d'une protomé, mais du visage d'une statuette. Compte tenu des dimensions probables de la tête (env. $9 \mathrm{~cm}$ ), la statuette devait être assez grande $(60 \mathrm{~cm}$ ?). Pâte beige clair [10YR 7/4], assez dure. Haut. cons. $6,8 \mathrm{~cm}$. Ép. de la croûte de 1 à

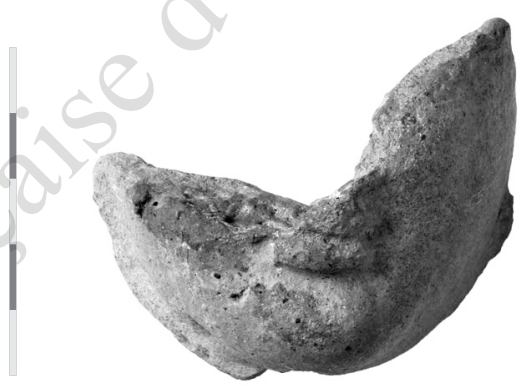

Fig. 18 - Bas d'un visage (7001.46) (cl. A. Barroche). $1,8 \mathrm{~cm}$. Date : fin $\mathrm{VI}^{\mathrm{e}} \mathrm{s}$.

7017.01 (Musée de Sitia, 10238 Vitrine, fig. 19) — Femme assise sur un fauteuil à dossier à oreillettes, les pieds posés sur un tabouret bas. Elle est vêtue d'un péplos collant, qui ne dégage que les pieds et masque les bras et les mains posées à plat sur les genoux, et d'un voile tombant sur les épaules qui couvre la stéphanè. Le visage, rapidement esquissé, est peu détaillé et porte pour seuls bijoux des boucles d'oreille. La statuette, pleine, est issue d'un moule unique; l'arrière n'est pas détaillé. Pâte gris beige clair [entre 10YR 7/3 et 6/3]. Couverte crème sur l'ensemble de la figurine, écaillée par endroits. Haut. $8,2 \mathrm{~cm}$; larg. trône $4,5 \mathrm{~cm}$. Date : début ve $s$.

7009.01 (Musée de Sitia, 10928, fig. 20) - Tête féminine coiffée d'un diadème orné de palmettes, tirée d'un moule bivalve. Arrachement du revers de la tête. Pâte rouge sombre, micacée [5YR 6/6]. Haut. cons. 4,8 cm. Date : fin ve s. 

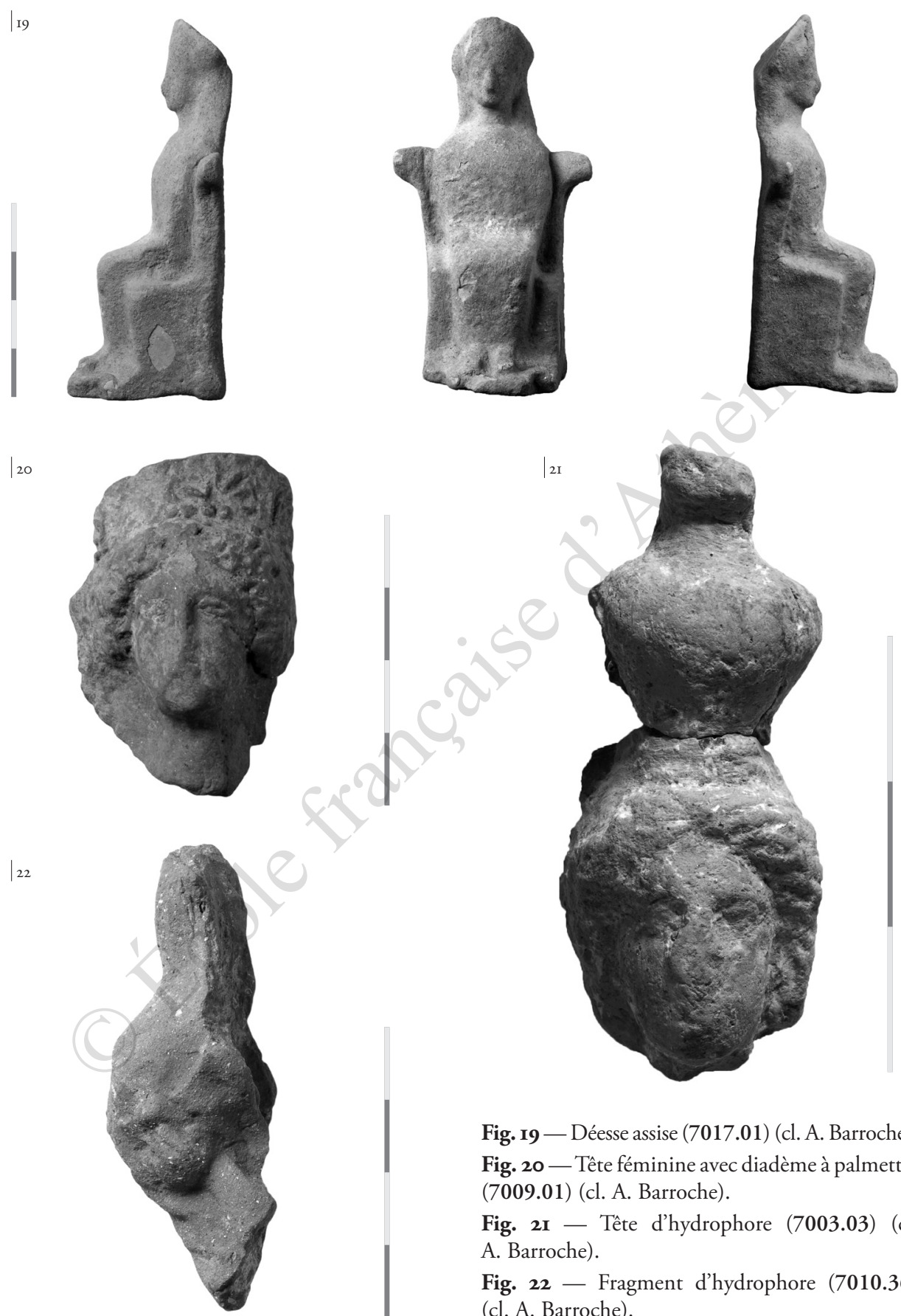

Fig. 19-Déesse assise (7017.01) (cl. A. Barroche). Fig. 20 - Tête féminine avec diadème à palmettes (7009.01) (cl. A. Barroche).

Fig. 2I - Tête d'hydrophore (7003.03) (cl. A. Barroche).

Fig. 22 - Fragment d'hydrophore (7010.36) (cl. A. Barroche). 
Nous reviendrons sur l'origine stylistique de 7001.46 et de 7017.01, qui trouvent divers parallèles en Crète. Quant à 7009.01, les fouilles d'Olynthe ont offert deux protomés qui en sont très proches, portant une stéphanè ornée de palmettes ${ }^{37}$. Un exemplaire du Louvre ${ }^{38}$ et une tête de Iasos ${ }^{39}$ portent semblable diadème, mais la chevelure n'est pas traitée de la même façon. Quelques têtes de la fin du ves. du Quartier des potiers à Corinthe s'en rapprochent ${ }^{40}$. Le décor du diadème évoque peut-être la couronne de la statue chryséléphantine d'Héra réalisée à Argos par Polyclète et considérée dans l'Antiquité comme son chef-d'œuvre; les monnaies de la cité en ont conservé la mémoire ${ }^{41}$. Le motif décoratif est suffisamment rare sur les diadèmes des statuettes en terre cuite pour que le parallèle soit intéressant et offre peut-être une indication chronologique.

Parmi les découvertes les plus intéressantes, malgré leur état indigent, signalons ces deux fragments d'hydrophore.

7003.03 (Musée de Sitia, 10924, fig. 2I) - Tête d'une hydrophore, brisée au cou, maintenant sur la tête une hydrie avec le bras droit, manquant. Le personnage porte une coiffure aux cheveux rayonnants. Issue d'un moule bivalve, la statuette ne présente plus guère que l'hydrie complète, ainsi que l'avers de la tête avec un visage peu détaillé, laissant apparaître à l'arrière des empreintes digitales, traces de l'enfoncement de la croûte dans le moule antérieur. Trace de peinture rouge sur la coiffure. Pâte très contrastée entre l'extérieur, gris jaune [10YR 7/3], et l'intérieur, gris foncé [10YR 4/1]. Peu ou mal cuit. Pâte micacée très dure à l'intérieur, tendre à l'extérieur. Haut. cons. $4,4 \mathrm{~cm}$. Sans le corps et le type vestimentaire, il est difficile de proposer une datation précise. La statuette ne paraitt toutefois pas antérieure à la fin du ve $s$.

7010.35 (Musée de Sitia, $10929 \alpha, \beta, \gamma, \delta$ + 4 fragments) + 7010.36 (Musée de Sitia, 10930, fig. 22) + 7010.37 (Musée de Sitia, $10931 \alpha, \beta)$ - Multiples fragments d'une statuette féminine moulée. 7010.36 (haut. cons. $6,8 \mathrm{~cm}$ ) figure un bras droit levé tenant un objet sur la tête. La main, assez peu détaillée, est une main droite : le petit doigt bien détaillé n'est pas le pouce, mais l'auriculaire. $7010.37 \alpha$ est un fragment de drapé (haut. cons. 4,2 cm). Il s'agit vraisemblablement d'une hydrophore.

Enfin, il faut rappeler la découverte, à l'intérieur de la construction rectangulaire (naos?) du fragment d'une grande statuette en terre cuite, qui s'ajoute - tant pour la taille que pour la typologie - aux fragments de marbre découverts au même endroit (voir supra, 7003.02, 04, 27, 28 et 29).

37. D. M. Robinson, Excavations at Olynthus IV. The Terracottas of Olynthus (1931), nos 297-298, p. 48-49, pl. 27.

38. S. Mollard-Besques, Catalogue raisonné des figurines et reliefs en terre cuite grecs, étrusques et romains I (1954), no C84 (Béotie, vers 430).

39. D. LevI, "Gli scavi di Iasos ", ASAA 45-46 (1967-1968), p. 573, fig. 45 c (fin ve s.).

40. A. N. Stillwell, The Potters' Quarter: The Terracottas. Corinth XV.2 (1952), no XVII, 12-13 (late 5th c.).

41. Voir P. Gardner, The Types of Greek Coins: An Archaeological Essay (1883), pl. viii; G. M. A. Richter, Sculpture and Sculptors of the Greeks ${ }^{4}$ (1970), fig. 698. 
7003.01 (Musée de Sitia, 10923, fig. 23)

- Fragment de draperie d'une statue en terre cuite. Pâte beige rouge clair [5YR 7/4], avec de gros dégraissants blancs et bruns. Dim. cons. 13,5 × 11,3 cm. Ép. 2 à 2,3 cm. Date : fin IVe$^{\mathrm{e}}$ III $\mathrm{e}$.

La courbure peu prononcée de ce fragment et sa dimension imposent de restituer une statue drapée d'au moins $80 \mathrm{~cm}$ de hauteur (soit la moitié de la taille naturelle), sinon plus, ce que confirme l'épaisseur de la croûte d'argile. Les statues de cette taille sont d'ordinaire modelées, et non moulées ${ }^{42}$; les plis présentent du reste des parties en creux, impossibles à extraire d'un moule. La qualité générale du modelé n'est guère remarquable, sinon pour

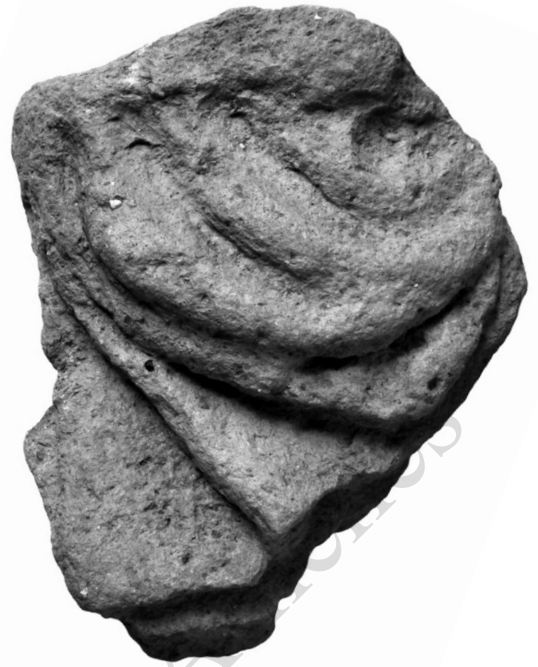

Fig. 23 - Fragment de draperie (7003.01) (cl. A. Barroche). son approximation. L'argile est grossière et offre un rendu de surface rugueux et peu précis. En dépit de la petitesse (relative) du fragment, on y reconnaîtra les plis d'un himation vraisemblablement noué sous la poitrine, qu'il s'agisse d'un type féminin ou masculin ${ }^{43}$. Ce type de drapé renvoie à des modèles du IV $s$.

\section{4. TANAgRÉENNES}

Le sanctuaire de Déméter à Cnossos a livré pour les années 325-200 un éventail très complet de tanagréennes ${ }^{44}$. Ces statuettes, bien attestées dans la nécropole d'Itanos ${ }^{45}$, sont également représentées au sanctuaire de Vamiès à travers quelques fragments peu significatifs, qui ne valent guère la peine d'être illustrés. Nous les listons ici pour ce qu'ils attestent des pratiques votives hellénistiques.

7010.38 (Musée de Sitia, 10932) — Fragment de drapé. Pâte beige gris [7.5YR 7/4 à 6/3]. Haut. cons. $1,9 \mathrm{~cm}$. Ép. $0,6 \mathrm{~cm}$.

42. Sur la grande plastique en terre cuite en Grèce, la synthèse de N. Bookidis, The Terracotta Sculpture, Corinth XVIII.5 (2010) (en particulier p. 35-80 sur la technique) vient combler un vide.

43. Voir G. S. Merker, The Terracottas Figurines of the Classical, Hellenistic, and Roman Periods, Corinth XVIII.4 (2000), no H85 (draped female); N. Bookidis (supra), no 52 (draped male).

44. R. A. Higgins, Knossos. The Sanctuary of Demeter (1973), p. 70-74.

45. A. Duplouy en prépare la publication pour le volume sur la nécropole d'Itanos. 
7004.18 (Apothèque de Palaikastro) — Fragment de drapé. Pâte rouge avec des inclusions blanches [2.5YR 5/6]. Haut. cons. 1,9 cm. Ép. 0,7 cm.

8135.16 (Apothèque de Palaikastro) — Fragment de drapé. Pâte beige rose au cœur gris, dure. Haut. cons. 3,9 cm. Ép. 0,7 cm.

8138.07 (Apothèque de Palaikastro) — Fragment de drapé. Pâte contrastée entre l'extérieur, jaune rose [7.5YR 7/6], et l'intérieur, gris [10YR 7/1]. Pâte micacée dure à l'intérieur, tendre à l'extérieur. Ép. $0,7 \mathrm{~cm}$.

8138.08 (Apothèque de Palaikastro) — Fragment de drapé. Bas de l'himation et pied (?) dépassant sous le vêtement. Pâte beige rouge [5YR 6/6], micacée, dure. Haut. cons. 2,6 cm; larg. $2,1 \mathrm{~cm}$. Ép. $0,7 \mathrm{~cm}$.

7003.06 (Musée de Sitia, 10925, fig. 24) - Cordon incurvé en terre cuite poinçonné de trois rangées de petits trous. Pâte rouge sombre [2.5YR 5/6]. Traces de peinture noire. L. cons. $2,5 \mathrm{~cm}$. Date : fin $\mathrm{II}^{\mathrm{e}} \mathrm{I}^{\mathrm{er}} \mathrm{s}$.

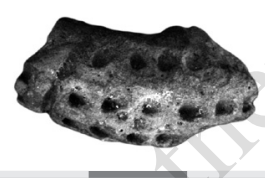

Fig. 24 - Fragment de couronne en bourrelet (7003.06) (cl. A. Duplouy).

Ce dernier fragment pourrait constituer une couronne en bourrelet, ornement d'influence égyptienne extrêmement répandu sur les figurines féminines de la fin du $\mathrm{II}^{\mathrm{e}}$ et $\mathrm{du} \mathrm{I}^{\mathrm{er}} \mathrm{s}$. av. J.-C. Le colombin d'argile formant la couronne est rajouté à la jonction de la face et du revers, et maintenu au revers par de la pâte appliquée avec les doigts ${ }^{46}$. Si l'identification est exacte, il s'agirait de la pièce la plus récente de la collection.

\section{IDENTIFICATION ET HISTOIRE DU SANCTUAIRE DE VAMIÈS}

La publication des figurines trouvées dans le sanctuaire de Vamiès est l'occasion de revenir sur une identification qui apparaît désormais mieux établie qu'elle ne l'était, notamment grâce aux parallèles que l'on peut établir entre notre matériel et divers autres dépôts votifs crétois. De même, ces terres cuites fournissent quelques indications supplémentaires sur l'histoire du site ainsi que sur les pratiques rituelles qui y avaient cours.

46. Voir A. Queyrel, Les figurines hellénistiques de terre cuite, Amathonte IV (1988), p. 167-168 et notamment pl. 62, fig. 647-648. Nombreux parallèles : S. Mollard-Besques, Catalogue raisonné des figurines et reliefs en terre-cuite grecs, étrusques et romains III (1971), pl. 287 (E/D 1536) et IV, 2 pl. 55; E. Töpperwein, Terrakotten von Pergamon (1976), no 315, p. 70, pl. 47; D. B. Thompson, Hesperia 21 (1952), no 70, p. 151, pl. 41 ; Hesperia 34 (1965), no T995, p. 64-65, pl. 21 ; P. G. LeyenaAr-Plaisier, Les terres cuites grecques et romaines: catalogue de la collection du Musée national des antiquités à Leiden (1979), no 876, pl. 119 (Myrina); D. B. Thompson, Troy: The Terracotta Figurines of the Hellenistic Period (1963), no 260, pl. LI; A. Laumonier, Les figurines de terre cuite, EAD XXIII (1956), no 615, pl. 61. 


\section{1. UN SANCTUAIRE DE DÉMÉTER}

La prospection du sanctuaire de Vamiès n'a pas livré d'inscription qui permettrait d'assurer l'identité de la divinité qui y était vénérée. Toutefois, la localisation du site, à quelque distance de la ville, évoque non seulement l'emplacement du sanctuaire de Déméter à Cnossos, mais aussi celui d'autres sanctuaires consacrés à cette divinité en Grèce ${ }^{47}$. C'est la raison qui nous avait fait proposer, dès 1996, d'en faire un sanctuaire de Déméter, peut-être associée à Koré. L'hypothèse a généralement été acceptée ${ }^{48}$. L'étude du matériel céramique et des terres cuites provenant du sanctuaire fournit d'autres indices qui viennent la conforter, en tout cas à partir de l'époque classique.

L'identité de la divinité vénérée à Vamiès ne peut en effet être assurée qu’à partir de l'époque classique. Pour les époques les plus anciennes, la religion crétoise, qui n'est pas directement assimilable à celle du panthéon olympien ${ }^{49}$, ne se laisse pas aussi aisément interpréter. Certaines figurines présentées dans le catalogue pourraient représenter la divinité du sanctuaire, mais l'identité n'en est pas facile à établir pour autant. La dame au polos (7001.47) pourrait en faire partie : sur d'autres sites en effet, il semble bien que ce soit la fonction assignée à ce type qui figure la déesse elle-même plutôt qu'une dédicante ${ }^{50}$. Néanmoins, son identité précise n'est pas clairement établie. Son iconographie renvoie à un type oriental, généralement désigné comme Astarté, dont la signification en Grèce n'est pas claire, qu'il s'agisse en l'occurrence de divinités locales ou de figures du panthéon grec (Aphrodite, Héra, Artémis, Athéna, Ilithyie). S. Böhm a plaidé en faveur d'une signification extrêmement générique, semblable à celle du prototype oriental ${ }^{51}$. Les trois protomés archaïques $(7017.22,7010.39$ et 7007.01) qui, là encore, représentent peutêtre la divinité, se rencontrent elles aussi dans une grande diversité de sanctuaires, sans qu'il n'y ait aucune spécialisation par divinité dans les types de visage ${ }^{52}$.

47. J. N. Coldstream, Knossos. The Sanctuary of Demeter (1973), p. 1. Sur la situation des sanctuaires de Déméter, voir S. Guettel-Cole, "Demeter in the Ancient Greek City and its Countryside ", dans R. Buxton (éd.), Oxford Readings in Greek Religion (2000), p. 133-154, qui cependant nuance la récurrence de cette disposition et envisage toute la diversité des localisations attestées.

48. Hypothèse initialement présentée dans BCH 121 (1997), p. 820-822; SporN 2002, p. 36-37 la fait sienne également.

49. Voir les remarques de J. Whitley, "The Chimera of Continuity: What Would "Continuity of Cult" Actually Demonstrate", dans A. L. D’Agata et A. VAn de Moortel (éds), Archaeologies of Cult. Essays on Ritual and Cult in Crete in Honor of Geraldine C. Gesell, Hesperia Suppl. 42 (2009), p. 279-288.

50. Pour une discussion complète du type, voir ERICKsON 2009, p. 364 et 376-377.

51. S. Bӧнм, Die nackte Göttin. Zur Ikonographie und Deutung unbekleideter weiblicher Figuren in der frühgriechischen Kunst (1990), p. 125-143.

52. Fr. Croissant, Protomés féminines archä̈ques (1983), p. 4. Notons qu’A. Muller, "Le tout ou la partie. Encore les protomés : dédicataires ou dédicantes? ", dans Cl. Prêtre, Le donateur, l'offrande et la déesse : systèmes votifs des sanctuaires de déesses dans le monde grec (2009) voit au contraire dans les protomés une représentation des dédicantes. 
Le type de la déesse assise sur un fauteuil à dossier (7017.01) est le plus communément attesté dans le sanctuaire de Déméter à Cnossos; R. A. Higgins a proposé d'y voir une représentation de la déesse elle-même, voire une reproduction de la statue de culte ${ }^{53}$. La popularité de ce type de statuettes dans d'autres sanctuaires crétois est manifeste : le type est fréquent dans le dépôt d'Olonte ${ }^{54}$, comme au thesmophorion de Gortyne ${ }^{55}$. L'exemplaire de Vamiès constitue en ce sens un élément significatif dans l'identification de la divinité vénérée. Sa présence ne constitue cependant pas à elle seule une preuve décisive puisque, si ce type est fréquent dans des sanctuaires de Déméter, il ne leur est nullement exclusivement réservé.

Les deux figurines d'hydrophores $(7003.03$ et $7010.35+7010.36+7010.37)$, que l'on situera vraisemblablement au IV s., sont en revanche plus significatives. Bien qu'il ne soit pas exclusivement réservé aux seuls sanctuaires de Déméter ${ }^{56}$, ce type de représentation est particulièrement commun, à travers toute la Grèce, dans les sanctuaires de cette déesse à l'époque classique et jusqu'au début de l'époque hellénistique ${ }^{57}$, comme c'est le cas au sanctuaire de Cnossos entre 425 et 350 ou à celui de l'Acrocorinthe ${ }^{58}$. La signification de l'hydrophore n'est pas absolument univoque : on pense naturellement à l'eau nécessaire à certains rituels et à la fonction de l'hydrie dans le culte, mais il peut également s'agir de la représentation d'une scène de la vie quotidienne des fidèles. Quelle qu'en soit l'interprétation, ces figurines confortent l'affectation du sanctuaire de Vamiès au culte de Déméter.

L'iconographie des figurines est donc un élément qui plaide en faveur d'un sanctuaire consacré à Déméter, à partir de la fin de l'archaïsme en tout cas. On peut également signaler que, parmi le matériel céramique provenant de Vamiès, ont été reconnus de probables fragments de kernoi ${ }^{59}$. S'il s'agit bien de ce type de vases, ils renforcent l'identification du sanctuaire, car on sait qu'ils étaient associés aux pratiques votives

53. R. A. Higgins (n. 44), p. 77-80, nos 142-168, pl. 52-55.

54. Voir BCH 85 (1961), p. 869, fig. 11; C. Davaras (n. 29), fig. 84.

55. N. Allegro et al., "Lo scarico del thesmophorion di Gortina », dans C. A. Di Stefano (éd.), Demetra. La divinità, i santuari, il culto, la leggenda. Atti del congresso internazionale. Enna, 1-4 luglio 2004 (2008), p. 108-109, fig. 6 .

56. À défaut d'hydrophores, les hydries, réelles ou miniatures, font également partie, par exemple, du matériel votif des sanctuaires d'Héra; voir J. D. BAUмBaCH, The Significance of Votive Offerings in Selected Hera Sanctuaries in the Peloponnese, Ionia and Western Greece (2004), p. 89 et 94-96 (Héraion d'Argos).

57. E. Dient, Die Hydria. Formgeschichte und Verwendung im Kult des Altertums (1964), p. 187-193; Cl. Rolley, « Le sanctuaire des dieux patrôoi et le thesmophorion de Thasos ", $B C H 89$ (1965), p. 476; R. A. Higgins (n. 44), nos 61-70 (p. 68-70) et p. 184; A. Queyrel (n. 46), p. 110; Sporn 2002, p. 325-326.

58. J. N. Colddtream (n. 47), p. 68-70 et 184, nos 61-70; G. S. Merker (n. 43), p. 38-42, nos C45-C69.

59. Tessons 7004.01 et 7011.01. Voir http://prospection-itanos.efa.gr, pour une description et un dessin de ces fragments. 
des sanctuaires de Déméter ${ }^{60}$. Ajouté aux figurines d'hydrophores et à la localisation du sanctuaire, cet indice paraît confirmer l'identification proposée. À Vamiès, Déméter était peut-être associée, comme il est fréquent, avec Koré, mais nous n’avons pu trouver aucun élément qui l'atteste avec certitude.

\section{2. Matériel et CUlte}

Il n'est pas aisé, dans le détail, de distinguer parmi les objets recueillis à Vamiès ceux qui pourraient avoir joué un rôle dans le rituel ou constituer un équipement du culte. La difficulté est d'autant plus importante que les objets ont tous été trouvés hors contexte et qu’on ignore dans quelles conditions ils étaient conservés dans le sanctuaire.

On pourrait être tenté de reconnaître une fonction cultuelle aux deux statuettes de grande taille qui ont été l'une et l'autre retrouvées dans l'édifice rectangulaire $-i$. e. le possible temple. La première est la statuette fragmentaire en marbre $(7003.02+7003.04$ $+7003.28+7003.27+7003.29)$ haute d'environ $80 \mathrm{~cm}$ de haut. Toutefois, elle est si mal conservée qu'on ne sait s'il s'agit d'une figure féminine ou masculine. Un fragment de drapé appartenant à une grande figurine de terre cuite (7003.01) - probablement, elle aussi, de $80 \mathrm{~cm}$ de haut - a été trouvé dans le même édifice. Il pourrait également s'agir d'une effigie cultuelle, mais le fragment conservé interdit toute restitution de la figure. La dimension ne constitue pas non plus un indice suffisant.

Il est parfois plus facile d'apprécier la fonction des objets : les statuettes et les protomés féminines étaient probablement des offrandes déposées - ou, pour certaines, suspendues - dans le sanctuaire; il en allait de même pour les vases miniatures dont plusieurs fragments ont été recueillis ${ }^{61}$. D'autres objets au contraire pouvaient y être conservés parce qu'ils jouaient un rôle spécifique dans le culte rendu aux divinités du sanctuaire. Ainsi, les fragments de kernoi déjà évoqués entreraient dans cette catégorie. Certains plats également pouvaient être utilisés lors de banquets rituels qui se seraient tenus dans le sanctuaire ${ }^{62}$. Les lampes ${ }^{63}$ - dont plusieurs exemplaires sont à becs multiples - ont

60. S. Xanthoudidis, "Cretan Kernoi», BSA 12 (1905-1906), p. 9-23; sur l'usage des kernoi dans les sanctuaires de Déméter, Chr. Mitsopoulou, «De nouveau Kernoi pour Kernos... Réévaluation et mise à jour de la recherche sur les vases de culte éleusiniens ", Kernos 23 (2010), p. 145-178.

61. Tessons 7017.03, 7018.01, 7033.02, 7039.12, 7039.16, 7039.17; les deux tessons 7004.01 et 7011.01 interprétés comme des fragments de kernoi pourraient être aussi des vases miniatures.

62. La lékanè (7039.20) par exemple pouvait jouer un rôle dans la consommation des repas; de même, des plats dont plusieurs fragments ont été découverts à Vamiès (7003.34, 7004.08, 7011.03, 7039.08). Sur ce matériel, on renverra aux études de N. Massar et d'A. Tsingarida dans A. Schnapp (éd.), Le territoire d'Itanos, à paraître.

63. Tessons 7001.14, 7003.21, 7011.07, 7017.05, 7039.11 et 8135.15. 
pu servir à l'éclairage de cérémonies nocturnes bien attestées dans le cadre des cultes de Déméter ${ }^{64}$.

Il est toutefois souvent difficile de proposer une interprétation univoque du matériel de Vamiès. Les fragments d'exaleiptra ${ }^{65}$ peuvent ainsi être interprétés soit comme une pratique votive (le don de parfum à la déesse), soit comme une pratique proprement cultuelle (l'usage d'huiles parfumées lors du rituel). À l'inverse, l'absence de certains types de vases est tout aussi difficile à justifier par des pratiques cultuelles particulières. Ainsi, aucun fragment de matériel culinaire ne provient du sanctuaire. Est-ce parce que les repas étaient préparés en un autre lieu? L'absence de certaines formes de vases à boire - notamment les canthares - doit-elle s'expliquer par le déficit quantitatif de la céramique de la fin de la période classique ou de la période hellénistique? Rend-elle compte au contraire de l'absence de consommation de vin dans le sanctuaire? Il est donc particulièrement périlleux de tenter de rapprocher le matériel recueilli au sanctuaire de Vamiès avec des rituels déterminés, d'autant qu’on ignore complètement dans quelles conditions étaient conservés ces objets.

\section{iII. 3. Chronologie du sanctuaire}

En ce qui concerne la chronologie du site, le matériel récolté permet tout d'abord d'assurer que le sanctuaire de Vamiès n'a pas, contrairement à l'hypothèse de M. Prent ${ }^{66}$, une origine protohistorique ("a BA origin»). Il est lié à la cité grecque d'Itanos et les plus anciennes traces d'activité, de quelque nature que ce soit, qu'on y relève ne remontent pas au-delà de l'époque géométrique : deux tessons (7004.19 et 7039.14) datent au mieux du $\mathrm{X}^{\mathrm{e}}$ ou du $\mathrm{IX}^{\mathrm{e}}$ s., deux autres (7017.17 et 8135.28$)$ de la fin du VIII $s$. Les terres cuites, quant à elles, ne sont pas antérieures, pour les plus anciennes, au $\mathrm{VII}^{e} \mathrm{~s}$. avec les types dédaliques. Elles donnent ensuite l'image d'une série continue d'offrandes jusqu'à la conquête romaine au moins, témoignant d'une activité cultuelle ininterrompue.

Il faut également réfuter l'hypothèse émise par Br. Erickson, qui suppose le rétablissement du culte vers 525-500, après un long hiatus au vi ${ }^{e} s{ }^{67}$. S'il n'existe à Vamiès

64. Pour Cnossos, J. N. Coldstream (n. 47), p. 186. Pour Gortyne, N. Allegro et al. (n. 55), p. 113. On songera aussi aux Nyktophylaxia de Délos, dont le lien avec Déméter a été établi par Fr. SoкоLowski, " Note sur les NYKTOФY $\Lambda$ A IIA de Délos ", BCH 59 (1935), p. 282-390.

65. Tessons : $7001.45,7010.51$ et 7017.21 .

66. Prent 2005, p. 310 (B. 48) évoque " the many known parallels in the area ", mais aussi des " megalithic BA buildings (...) at Vamies near Itanos » (p. 553) qui n'existent pas.

67. Br. L. ERICKson, Crete in Transition. Pottery Styles and Island History in the Archaic and Classical Periods (2010), p. 268. 
- comme d'ailleurs à Cnossos ${ }^{68}$ - aucune terre cuite archaïque particulièrement représentative du $\mathrm{VI}^{\mathrm{e}} \mathrm{s}$., la céramique y est attestée tout au long du siècle, en particulier sous la forme d'importations de Corinthe et de Grèce de l'Est, et témoigne ainsi d'une activité cultuelle ininterrompue. Après les protomés de la fin de l'archaïsme, les figurines en terre cuite sont ensuite bien attestées à l'époque classique et durant toute la période hellénistique, notamment par une série de fragments de tanagréennes. Certes, la majorité des figurines appartiennent aux époques orientalisante, archaïque et classique, les statuettes hellénistiques n'y constituant que la portion congrue. La fréquentation, importante du viII ${ }^{e}$ au ve s., pourrait ainsi avoir été moindre à partir du IVe s., si l'on en juge par les terres cuites et par le nombre de tessons assurément datables de la période $\mathrm{IV}^{\mathrm{e}}-\mathrm{II}^{\mathrm{e}} \mathrm{s} .{ }^{69}$. La découverte la plus récente en matière de terres cuites pourrait être cette couronne en bourrelet (7003.06) appartenant, si l'identification est correcte, à une statuette de la fin du $\mathrm{II}^{\mathrm{e}}$ ou du $\mathrm{I}^{\mathrm{er}}$ s. av. J.-C. Il est cependant risqué de se fonder sur les seules trouvailles mobilières pour avancer une telle proposition: si l'on considère l'architecture et si l'on admet que l'édifice rectangulaire date de l'époque hellénistique, l'image que l'on retire de la fréquentation du sanctuaire est bien différente.

La durée de l'activité cultuelle attestée à Vamiès en fait incontestablement un lieu de culte important de la cité d'Itanos, qui le rapproche d'autres sanctuaires civiques comme celui de Cnossos. Une telle continuité contraste en revanche avec la brièveté d'occupation des petits sanctuaires ruraux d'Olonte, de Sitia ou de Roussa Ekklesia. À la différence de ces derniers, où le culte se déroulait exclusivement en plein air à proximité d'une source, le sanctuaire de Vamiès offre la trace de vestiges architecturaux clairement mis au jour par les nettoyages que nous y avons effectués et qui attestent sa monumentalisation. La date des constructions est malheureusement - on l'a vu - mal établie, car le site n'a pas été fouillé. Les fondations de l'édifice rectangulaire ne sont donc pas datées précisément. On a dit qu'il pouvait être relativement tardif; cependant, quelques fragments de tuile (7017.36 et 7018.02) portent sur la surface extérieure un engobe brun noir caractéristique de la période archaïque, ce qui laisse croire qu'il a pu exister un bâtiment couvert à Vamiès dès une époque assez haute, soit avant même le sanctuaire de Déméter à Cnossos qui ne dispose pas de temple avant l'époque classique.

Enfin, notons que la zone de Vamiès fut encore occupée au-delà de l'Antiquité : comme nous l'avons vu, certains aménagements sans rapport avec le sanctuaire y ont été faits à une date difficile à préciser (l'aire de battage par exemple et peut-être la construction située une trentaine de mètres au Nord-Ouest); des tessons appartenant à

68. À Cnossos, une seule figurine paraît dater du vie s., voir R. A. Higgins (n. 44), p. 59, no 11; J. N Coldostream, G. L. Huxley, « Knossos: the Archaic Gap », BSA 94 (1999), p. 292.

69. N. Massar a procédé à ce décompte dans son étude (à paraitre dans A. Schnapp [éd.], Le territoire d'Itanos) et en tire les conclusions prudentes qui s'imposent. 
des époques postérieures à l'Antiquité ont été recueillis, surtout dans les parties Sud et Ouest de la zone prospectée ${ }^{70}$.

Il est certain que la fouille complète du sanctuaire permettrait de préciser le panorama que nous avons tenté d'esquisser ici, alors même que la présence d'une bergerie moderne à proximité immédiate et le déploiement de ses activités constituent une menace réelle pour la pérennité des structures et des informations qu'elles recèlent encore sur la nature, l'importance et la chronologie du culte.

\section{ORIGINE, STYLE ET DISTRIBUTION DES TYPES}

Outre les informations qu'elles fournissent sur les cultes du sanctuaire de Vamiès et sur l'histoire de cet établissement, les terres cuites dont nous avons dressé plus haut le catalogue permettent d'esquisser les contours d'une évolution dans les rapports des gens d'Itanos avec les cités des environs. En analysant la provenance des figurines, il est en effet possible de faire la part des importations étrangères et des productions locales ou - plus exactement - régionales. S'il n'a pas été possible de reconnaître une production proprement itanienne, nous verrons en effet qu'il s'agit néanmoins de modèles de Crète de l'Est, attestés dans des sites proches d'Itanos. Enfin, les quelques figurines de style dédalique qui proviennent de notre sanctuaire invitent à revenir sur la question souvent abordée dans la bibliographie de l'identité des cités crétoises et des formes artistiques qu'elle serait susceptible de revêtir.

\section{1. ANAlyse typologiQue ET STYlistiQue : LE DÉPôt EN CONTEXTE RÉgional}

Il n'est pas aisé de déterminer l'origine des productions représentées au sanctuaire de Vamiès. La diversité des argiles employées dans une collection au demeurant peu nombreuse et assez diversifiée, tant d'un point de vue typologique que chronologique, rend en effet aléatoire l'identification d'une production spécifiquement liée à Itanos. La plupart des terres cuites provenant du sanctuaire de Vamiès apparaissent, en ce sens, comme des importations, et seuls la typologie et le style donnent une indication sur l'origine des pièces. Aucune étude archéométrique n’ayant par ailleurs été menée sur les céramiques et terres cuites d'Itanos, il n'est pas possible en l'état actuel de la recherche d'assurer l'existence d'une production propre à notre cité, clairement caractérisée par une argile dont l'origine serait connue. Ces précautions prises, l'analyse stylistique de ce matériel

70. Des tessons appartenant aux périodes paléochrétienne, byzantine, vénitienne ou turque ont été recueillis dans les secteurs de ramassage suivants : 7001, 7006, 7003, 7015, 7019, 7022, 7023, 7025, 7026, 7029, 7030, 7031, 7035, 7037, voir http://prospection-itanos.efa.gr. 
et les comparaisons qu'il permet avec d'autres dépôts de Crète ou de Grèce permettent de relever les origines possibles des pièces de ce dépôt et, partant, de formuler quelques hypothèses prudentes sur ce qu'elles nous révèlent de l'histoire de la cité d'Itanos.

Il semble que les objets les plus anciens, les terres cuites dédaliques $(7001.47,7001.35$ et 7017.02), constituent une production régionale, dont le style ou la typologie sont clairement associés à la Crète de l'Est.

Tel est le cas, en particulier, de la dame au polos (7001.47). S. Böhm a proposé de distinguer plusieurs styles dans l'abondante production crétoise de ce type orientalisant; elle les fait correspondre à autant de productions locales ${ }^{71}$. Par ses caractéristiques, la dame au polos de Vamiès rentre dans une série bien documentée en Crète de l'Est. Notre exemplaire est ainsi très proche d'une plaquette du Louvre conservée en buste; celle-ci fut offerte au musée en 1902 par G. Arnaud-Jeanti comme provenant de Sitia, sans plus amples précisions sur le contexte archéologique de découverte ${ }^{72}$. La dame au polos de Vamiès se rapproche en outre de pinakes provenant du dépôt de Vavelloi à Praisos, dont seuls deux exemplaires, du musée d'Héraklion et du Metropolitan Museum, ont été publiés en détail ${ }^{73}$. Il s'agit du type 2 défini par E. Forster, dont de nouveaux exemplaires ont été mis au jour en 1998 par J. Whitley ${ }^{74}$. Les meilleurs parallèles se rencontrent en effet, lorsque leur provenance exacte est connue, dans l'arrière-pays de Sitia. Si rien de ce qui a été publié par N. Papadakis du riche dépôt votif dédalique découvert dans la ville de Sitia ne s'en rapproche exactement, plusieurs pièces de ce dépôt, exposées au musée de Sitia, présentent néanmoins une typologie similaire : divinité, nue ou habillée (les deux types sont attestés), portant un haut polos et une coiffure à parotides; toutes celles-ci sont malheureusement inédites. Il en va de même pour les exemplaires de Lapsanari ${ }^{75}$, localité de l'arrière-pays de Sitia qui a livré plusieurs pièces comparables, elles aussi exposées dans les vitrines du musée. Seules les plaquettes de Roussa Ekklesia sont depuis peu publiées : on y retrouve une petite centaine d'exemplaires fragmentaires appartenant au

71. S. Вӧнм (n. 51), p. 73-75.

72. S. Mollard-Besques (n. 38), no B165, pl. 21 (645-640). Les objets offerts au Louvre en 1902 par la famille Arnaud-Jeanti semblent avoir été recueillis en 1893 lors d'un voyage en Crète de Gaston ArnaudJeanti; voir BAntFr 66 (1905), p. 151.

73. Héraklion, Musée archéologique, no 1219 : R. A. Higgins, Greek Terracottas (1967), pl. 10, fig. E. New York, Metropolitan Museum no 53.5.23 : F. Halbherr (n. 32), p. 385, pl. X, fig. 1; E. H. Dohan (n. 35), p. 220, fig. 25; Erickson 2009, p. 359, fig. 5. Deux des trois pièces de ce type conservées au British Museum, données par l'École britannique d'Athènes à la suite de fouilles effectuées en 1901 à Praisos, viennent probablement du sanctuaire de Vavelloi; voir R. A. Higgins, Catalogue of the Terracottas. British Museum I (1954), p. 160 et pl. 76 (nos 585-587).

74. E. S. Forster, BSA 11 (1904-1905), p. 244 (type 2); AR 45 (1998-1999), p. 122, fig. 157-158. Il s'agit du type III/15 (670/65-640) de Pilz 2011, p. 196-197.

75. N. Platon, AD 16 (1960), p. 261 ; id., CretChron 14 (1960), p. 526 ; P. Faure, "Sur trois sortes de sanctuaires crétois (suite) ", BCH 93 (1969), p. 207; Prent 2005, p. 302 (B. 43); Pilz 2011, p. 118-119. 
même type ${ }^{76}$. Ajoutons à cela les trois plaquettes découvertes par N. Schlager à l'occasion du survey du plateau de Ziros sur le site de Moulas, petit sanctuaire de hauteur qui pourrait appartenir au territoire de Praisos ${ }^{77}$. Notre exemplaire se distingue en revanche assez nettement des plaquettes de Gortyne et d'Axos, même les plus ressemblantes ${ }^{78}$, en particulier par la séparation de la masse capillaire en plusieurs parotides lisses, non distribuées en perles ou en perruque à étages, quoique ce type soit également attesté dans les dépôts de Sitia et de Praisos. La dame au polos de Vamiès constitue en ce sens un type caractéristique de Crète orientale, qui paraît particulièrement bien représenté dans les sanctuaires du territoire de Praisos.

La plaquette 7001.35 est plus difficile à étudier et nous avons vu que son état rendait incertain la restitution du motif. Cependant, les meilleurs parallèles que nous avons pu trouver proviennent des sanctuaires de la cité de Praisos ("Fourth Terrace » et Vavelloi) ou de son territoire (Roussa Ekklesia, Sitia, Stou Koukou to Kephali, Prophitis Ilias). Ce sont eux qui nous ont incités à reconnaître l'image d'un personnage court vêtu dont seuls sont conservés les pieds. Nous aurions donc avec ce fragment la trace à Itanos d'un autre type de la petite plastique de Crète orientale, particulièrement bien représenté dans les sanctuaires du territoire de Praisos.

Quant à la tête moulée pleine 7017.02, qui devait vraisemblablement s'encastrer dans un corps cylindrique, si sa typologie renvoie clairement à une production de Crète de l'Est, il n'en est rien du style, qui ne correspond à aucun exemplaire du dépôt archaïque de Sitia, où la " perruque à étages » et une physionomie globalement " dédalique » dominent. La douceur des traits n'a d'ailleurs rien de la plastique crétoise et renvoie au contraire à un visage de Grèce de l'Est. Il semble qu'il s'agisse d'une adaptation locale, selon un type dédalique, d'une protomé ionienne du $\mathrm{VI}^{\mathrm{e}}$ s., qui aurait été surmoulée ${ }^{79}$. La prise d'empreinte sur une terre cuite importée expliquerait en outre l'estompement général des détails, qui interdit d'ailleurs de préciser l'origine exacte du prototype. Mentionnons à ce propos la présence dans le dépôt d'Olonte de plusieurs protomés ioniennes signalées par Fr. Croissant. Pour autant que l'on puisse en juger, la forme générale du visage, pleine et

76. ERICKSON 2009, p. 358-365, nos 4-97.

77. N. Schlager, Archäologische Geländeprospektion Südostkreta. Erste Ergebnisse (1991), p. 22-23, pl. 24. Voir Pilz 2011, p. 105.

78. Voir G. Rizza et V. S. M. Scrinari, Gortina. II. Il santuario sull'Acropoli di Gortina (1968), no 60a, $111,142,150,153$, etc. (parotides en rangs de perles), no 91 (masse capillaire non séparée en parotides), nos 148, 137, 138, 129, etc. (perruque à étages). Même chose pour les exemplaires d'Axos, qui portent soit la perruque à étages (nos 39, 40, 48), soit les parotides en rangs de perles (nos 53-55); voir G. RizzA, "Le terrecotte di Axos ", ASAtene 45-46 (1967-1968), p. 211-302. Voir aussi P. Blome (n. 36), pl. 12-15.

79. Une tête de Praisos, qui n'affiche manifestement pas un style crétois, offre peut-être un cas analogue; voir F. Halbherr (n. 32), p. 388, pl. xi, no 5. 
légèrement allongée, ainsi que le menton arrondi et empâté ne sont pas sans évoquer les protomés du groupe $\mathrm{C}$ (Chios) représentées à Olonte ${ }^{80}$.

Au VII $\mathrm{s}$. donc, les terres cuites retrouvées à Vamiès paraissent des productions propres à la Crète de l'Est et, plus précisément sans doute, à la cité de Praisos, où l'on trouve des parallèles convaincants et vraisemblablement une origine aux trouvailles de Vamiès. Rapidement pourtant, les modèles stylistiques extérieurs sont présents, tantôt à travers des pièces d'importation, tantôt à travers des adaptations crétoises. On trouve ainsi l'écho des productions ionienne, corinthienne et attique dès la fin du vi ${ }^{e}$ s., avant l'arrivée des tanagréennes à l'époque hellénistique.

La morphologie particulière de la protomé à plastron 7017.22 dérive des appliques de pyxide $^{81}$. Elle est inconnue en dehors du domaine corinthien et n'est pas antérieure à la fin du $\mathrm{VI}^{\mathrm{e}}$ s. Morphologiquement, notre exemplaire se rapproche du type S1 de Fr. Croissant, issu d'un atelier de Grèce centrale : adaptant le modèle corinthien ${ }^{82}$, le coroplathe a refermé le haut du diadème, ce qui permet de rejeter en arrière le trou de suspension d'ordinaire placé à l'avers des protomés corinthiennes. Le visage est allongé et étroit. Si le nez est cassé, la bouche est peu enfoncée et le menton peu saillant ou proéminent. La masse des cheveux, résumée par un rouleau frontal, est indistincte. Tel quel, ce visage ne correspond guère aux types du groupe $\mathrm{M}$ (Corinthe) ou $\mathrm{S}$ (corinthianisant) de Fr. Croissant, qui offrent des visages surmontés du polos et encadrés de la perruque à étages. Bien que la coiffure, à peine esquissée, soit étrange en domaine corinthien, notre exemplaire ne paraît pas moins avoir un visage corinthien, peut-être ancien : des parallèles existent ${ }^{83}$. Il semble en fait s'agir d'une adaptation corinthianisante, peut-être crétoise. Une pièce très semblable, tant du point de vue de la morphologie (protomé à plastron, percée d'un trou de suspension sur le sommet de la tête) que du style (visage allongé et étroit), a été découverte dans le dépôt d'Olonte. Elle est inédite, mais exposée au musée d'Agios Nikolaos.

Le fragment 7001.46 présente un visage féminin dont la bouche, très charnue, est particulièrement étroite et pincée. Elle révèle un visage racé et aisément reconnaissable, qui renvoie à des modèles de Grèce de l'Est, peut-être à des types chiotes. Rappelons que des protomés chiotes ont été découvertes dans le dépôt d'Olonte (voir supra).

Enfin, la statuette de déesse assise sur un fauteuil à dossier 7017.01 ressortit à un type bien connu de la plastique attique de la fin de l'époque archaïque et du début de

80. Fr. Croissant (n. 52), nos 39, 48, 50, 51, 52 (pl. 20, 25-27).

81. Pour le type, Fr. Croissant (n. 52), p. 20-21.

82. Voir A. N. Stillwell (n. 40), p. 97-98 et no II, 8-14.

83. Voir certaines appliques de pyxide : H. Payne, Necrocorinthia. A Study of Corinthian Art in the Archaic Period (1931), pl. 48, no 5 (vase no 892). 
la période classique $(510-460)^{84}$. Il pourrait s'agir ici d'une importation attique ou d'une imitation crétoise, comme celles découvertes en abondance dans le sanctuaire de Déméter à Cnossos ${ }^{85}$.

Ainsi, par rapport aux figurines plus anciennes qui paraissent relever de productions de Crète orientale, les types féminins de la fin de l'archaïsme et du classicisme marquent une diversification des emprunts typologiques et stylistiques. La petite plastique de Vamiès trahit aussi une certaine homogénéisation des offrandes au sein des sanctuaires crétois, puisque la situation est identique à considérer les sanctuaires de Cnossos et d'Olonte.

\section{2. Distribution deS TYPES DÉdALIQUES ET IDENTITÉ ÉTÉOCRÉTOISE}

La découverte à Vamiès de quelques terres cuites dédaliques - maigre échantillon de ce qu'une fouille complète du sanctuaire pourrait livrer? - mérite qu’on leur consacre une discussion approfondie, en relation avec les identités collectives auxquelles l'historiographie les a d'ordinaire associées. La publication de ces trois types dédaliques offre en effet l'occasion de s'interroger sur leur distribution régionale et de poser la question des identités stylistiques dont ils étaient à la fois porteurs et vecteurs. Aussi réduit soit notre échantillon, les trois types dédaliques attestés à Vamiès apportent en effet, par les parallèles qu'ils rencontrent dans les sanctuaires de l'arrière-pays de Sitia, des éléments nouveaux dans la discussion de la petite plastique archaïque de Crète orientale et de l'identité étéocrétoise qui leur a souvent été prêtée ${ }^{86}$.

Dès le début du xxe s., les fouilleurs de Praisos ont souligné les particularités de la production coroplastique locale, mise en évidence à travers plusieurs dépôts votifs. Si F. Halbherr s'en tenait à une prudente mise en garde ${ }^{87}$, la spécificité de ces terres cuites a rapidement été mise au crédit d'une identité étéocrétoise, telle qu'esquissée à partir des auteurs anciens (Homère, Hérodote et Strabon en particulier) et des inscriptions

84. Voir P. G. Leyenaar-Plaisier (n. 46), nos 7-12, pl. 2; N. Breitenstein, Danish National Museum. Catalogue of Terracottas: Cypriote, Greek, Etrusco-Italian and Roman (1941), no 175, pl. 20 ; B. VIERNEISELSchlörB, Die Figürlichen Terrakotten. I. Spätmykenisch bis späthellenistisch. Kerameikos XV (1997), nos 65-89; R. A. Higgins, Catalogue of the Terracottas. British Museum I, nos 655-661, p. 85-86; R. A. Higgins, Greek Terracottas, pl. 30C.

85. R. A. Higgins, Greek Terracottas, p. 60 "local adaptation of an Attic type »; R. A. Higgins (n. 44), p. 77-80, nos 142-168, pl. 52-55.

86. Nous n'entrons pas dans la présentation des sources littéraires et épigraphiques relatives aux Étéocrétois; voir D. Viviers, "Vrais et faux Crétois. Aspects de l'autochtonie en Crète orientale », Topoi 6 (1996), p. 205-220 (avec bibliographie antérieure).

87. F. Halbherr (n. 32), p. 380 : «whoever might be tempted from local circumstances to attribute any among the most rudimental of the terra-cottas to the Eteocretans of Praesos, would have to come to the conclusion that their art scarcely differed from that of the Greeks ». 
découvertes à Praisos même. Ainsi, E. S. Forster écrivait : "Their interest lies not so much in their artistic merit as in the light they throw on the customs and beliefs of the Eteocretan people during a long period extending from the archaic to the Hellenistic age " et, plus loin, "In this period the types are hieratic, and probably had a close connection with the religious beliefs of the Eteocretan people ${ }^{88}$.

Depuis les années 1960, plusieurs dépôts votifs ont été fouillés dans l'arrière-pays de Sitia à l'occasion d'interventions ponctuelles du service archéologique grec (Roussa Ekklesia, Lapsanari, etc.), mais leur découverte n’a donné lieu qu'à de brèves notices.

Avec la reprise des travaux archéologiques britanniques à Praisos en 1992, quelques pièces supplémentaires ont été ajoutées aux collections déjà connues. Ce fut donc l'occasion pour J. Whitley de reprendre la discussion et de revenir sur la définition d'une culture matérielle étéocrétoise. Entre-temps, la notion même d'identité ethnique avait bien entendu fortement évolué ${ }^{89}$. À l'instar de F. Halbherr, J. Whitley s'en est tout d'abord tenu au constat d'un non liquet : " the differences between 'Eteocretan' and other Cretan terracottas of Archaic date are not so great that they warrant a special label » et de conclure : "Certainly there is little in the material culture of the Praisos area to mark out the Eteocretans from their Greek-speaking neighbours in Hierapytna or Itanos $"{ }^{90}$. Revenant sur cette affirmation initiale, il tend aujourd'hui à accentuer l'originalité de la culture matérielle de Praisos. Selon lui, elle se manifeste avant tout dans les lieux de culte. De ce point de vue, à côté de la topographie et de l'absence de monumentalisation des sanctuaires, les terres cuites archaïques jouent un rôle important dans la définition d'un faciès spécifique. "The (principally Archaic) terracotta plaques from the spring shrine at Roussa Ekklesia and the 'ruin cult' at Stou Koukou to Kephali are not only of the same types as those from the Spring at Vavelloi; often too they are from the same mould ", écrit-il. Elles constituent en ce sens " a distinctive range of locally produced and locally consumed terracotta plaques and figurines » et contribuent à définir « a distinctive 'Eteocretan' material culture, at least in cult». J. Whitley souligne en particulier le soin qu'auraient pris les habitants de Praisos à se distinguer de leurs voisins du Nord, la cité étant en conflit avec Itanos pour le contrôle du sanctuaire de Zeus dictéen à Roussolakkos (qui n’a pas, quant à lui, livré de figurines en terre cuite) : "Apart from this temple, it is the shrines of Stou Koukou to Kephali and Roussa Ekklesia which are closest to the 'border' with Itanos, and it is a remarkable fact that it is these shrines - Roussa Ekklesia in particular - which have the clearest affinities with the shrines around Praisos itself. Roussa Ekklesia is a spring shrine like the 'Spring at Vavelloi' and the figurines from this

88. E. S. Forster, BSA 11 (1904-1905), p. 243 et 257.

89. En particulier J. Hall, Ethnic Identity in Greek Antiquity (1997).

90. J. Whitley, « From Minoans to Eteocretans: the Praisos Region, 1200-500 BC », dans W. G. Cavanagh, M. Curtis (éds), Post-Minoan Crete (1998), p. 27-39, en particulier p. 37 (citations, p. 37 et 38). 
shrine are almost identical». Et de conclure : "I would argue that all this indicates the deliberate marking out, and hardening, of symbolic boundaries not only between the two neighbouring poleis of Praisos and Itanos, but between the ethnos of the 'Praisioi' and the Greek speakers around them ", tout en insistant : "It is the boundaries with Itanos that the Praisians took so much trouble to emphasise and to symbolise, in various material ways $»^{91}$.

Offrant une publication détaillée des terres cuites de Roussa Ekklesia, Br. Erickson est revenu, tout récemment, sur la question. Bien que sceptique sur l'existence d'un style étéocrétois spécifique à Praisos (notamment pour la céramique archaïque ${ }^{92}$ ), il souligne lui aussi les multiples affinités typologiques entre les divers ensembles votifs du territoire de Praisos, en particulier entre les dépôts de Roussa Ekklesia et de Vavelloi, et note la similitude des argiles employées pour les terres cuites de Praisos, Vavelloi et Roussa Ekklesia. En revanche, il oppose ces dernières aux figurines du dépôt votif de Sitia, tant par les types représentés que par l'argile utilisée. Il en tire d'ailleurs argument pour considérer que les sanctuaires de Sitia et de Roussa Ekklesia appartenaient à des cités différentes ${ }^{93}$.

Malgré l'exiguïté de l'échantillon collecté à travers le nettoyage de surface, la publication des terres cuites de Vamiès impose de revenir sur la distribution de ces trois types dédaliques (fig. 25), ce qui permettra aussi de faire le point sur les identités locales prêtées à ces terres cuites. Rappelons qu'en l'absence d'analyse pétrographique, il est difficile d'apporter quelque certitude sur l'origine des productions. De même, notre méconnaissance des ressources minéralogiques locales autant que l'absence de tout four de potier fouillé dans la région ne permettent pas de déterminer avec certitude le lieu de production.

- La dame au polos de Vamiès (7001.47, fig. 12) appartient à un type de Crète de l'Est présent dans les dépôts votifs de Sitia, Lapsanari, Roussa Ekklesia, Vavelloi et Moulas. Il n'est pas exclu qu'elle ait été tirée du même moule que certains exemplaires de Roussa Ekklesia et de Vavelloi, comme c'est le cas pour certaines plaquettes de ces deux sanctuaires. Par ailleurs, l'argile beige rosée, contenant de petites inclusions blanches et brunes, de la plaquette de Vamiès n'est pas sans rappeler les exemplaires

91. J. Whitley, "Identity and Sacred Topography: The Sanctuaries of Praisos in Eastern Crete", dans A. H. Rasmussen, S. W. Rasmussen (éds), Religion and Society: Rituals, Resources, and Identity in the Ancient Graeco-Roman World (2008), p. 235-248 (citations, p. 244 et 246). Voir aussi J. WhitLeY, "Praisos: Political Evolution and Ethnic Identity in Eastern Crete ca. 1400-300 B.C.", dans S. Deger-Jalkotzy, I. S. Lemos (éds), Ancient Greece: From the Mycenean Palaces to the Age of Homer (2006), p. 597-617, en particulier p. 609-610.

92. ERICKSON 2009, p. 387, n. 164 : "Pottery styles contemporary with the plaques do not seem to overlap with political or ethnic boundaries ». Voir aussi Prent 2005, p. 549.

93. ERICKSON 2009, p. 378-385. 


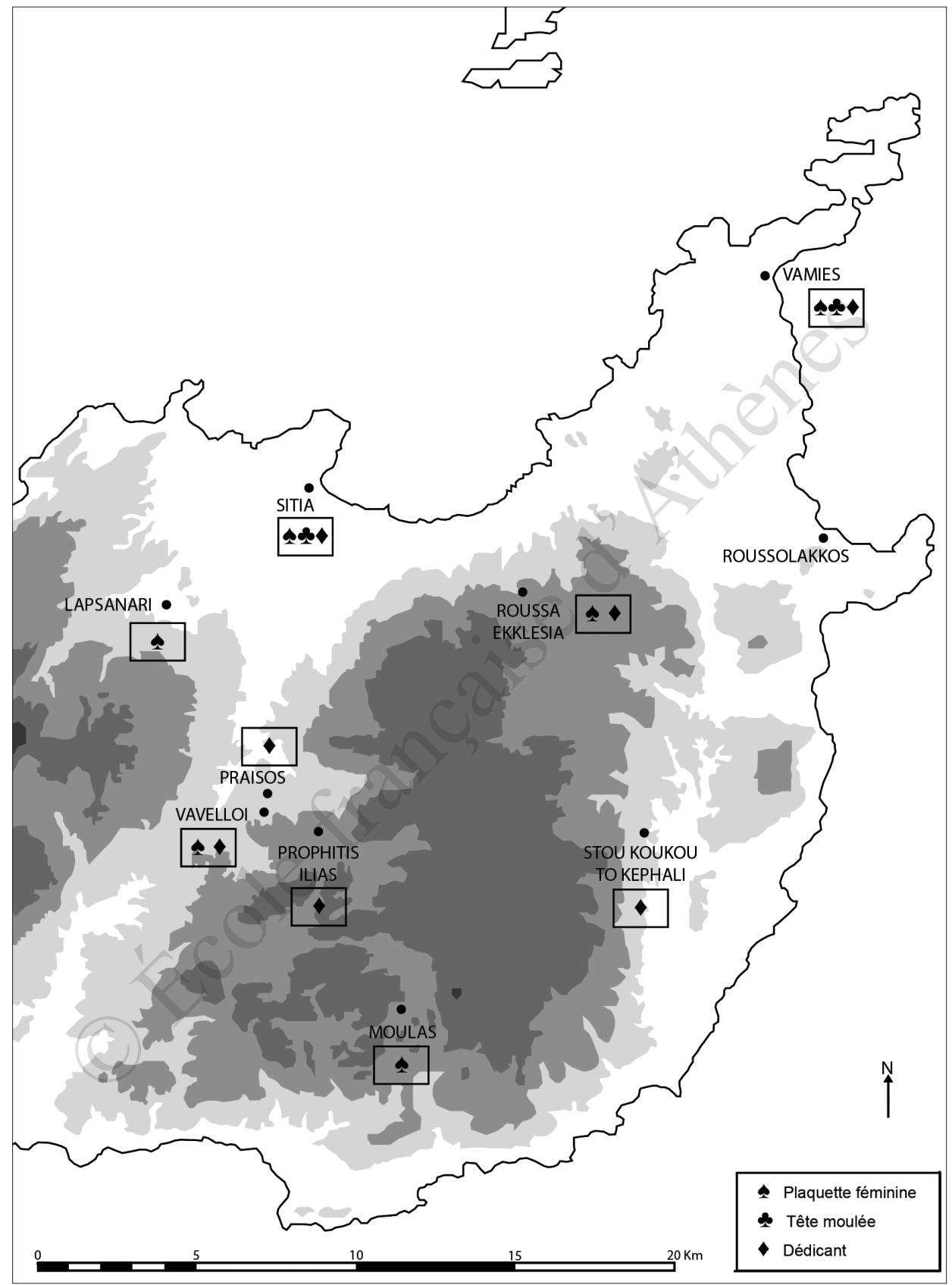

Fig. 25 - Distribution des types dédaliques attestés à Itanos (carte A. Duplouy). 
de Roussa Ekklesia ${ }^{94}$, auxquels on peut directement la comparer dans les vitrines du musée de Sitia, et ceux de Vavelloi ${ }^{95}$.

- La tête féminine pleine de Vamiès (7017.02, fig. 15) correspond à un type bien représenté dans le dépôt votif de Sitia, quoique le style en soit totalement distinct. Pourtant, si le type n'est pas représenté dans les sanctuaires du territoire de Praisos, il n'est pas vrai, comme l'écrit Br. Erickson, que l'argile des figurines de Sitia ("a distinct red clay with a gritty consistency ", p. 380) est radicalement différente de ce que l'on trouve dans les terres cuites de Roussa Ekklesia. Au moins trois plaquettes de Roussa Ekklesia (nos 1-3), qu'il considère comme les plus anciennes d'un point de vue chronologique, présentent cette même argile. La tête de Vamiès est, elle aussi, faite de cette argile rouge aux grosses inclusions; elle vient ainsi confirmer qu'il n'est pas invraisemblable de trouver les deux argiles dans le même sanctuaire pour des offrandes différentes, sans pour autant offrir d'indication sur le lieu de production.

- Le dédicant en tunique courte de Vamiès (7001.35, fig. 13-I4) correspond, si l'on accepte la restitution proposée, à un type régional qui, comme le note Br. Erickson, provient presque exclusivement de sanctuaires de la région de Praisos ${ }^{96}$, en l'occurrence de Sitia, Praisos («Fourth Terrace »), Vavelloi, Prophitis Ilias, Roussa Ekklesia et Stou Koukou to Kephali. Il convient à présent d'ajouter, avec Vamiès, un point supplémentaire sur la carte de distribution de ce type. Ajoutons que l'argile de la plaquette de Vamiès, semblable à celle de la dame au polos, pourrait être celle des terres cuites de Roussa Ekklesia.

Labondance des découvertes effectuées dans le territoire de Praisos et l'absence de tout parallèle connu ailleurs en Crète orientale ont naturellement poussé J. Whitley à faire de Praisos le grand centre régional de production de ces terres cuites dédaliques: «Praisos was clearly the major producer of terracottas in the sixth century, in East Crete if not in Crete as a whole, and there is nothing to suggest that a similar level of technical accomplishment had been attained by the coroplasts of Itanos $~^{97}$. Aucune découverte effectuée à Itanos ne vient effectivement remettre en question cette hypothèse sur le lieu de production des terres cuites. On pourrait donc admettre qu'elles sont des productions praisiennes. En revanche, la présence de ces trois types dédaliques à Itanos impose de

94. ERICKSON 2009, p. 357-358 : « reddish yellow (7.5R 7/6) to pale brown (10YR 7/4) », "clay (...) fine and compact ", " inclusions (...) small and white calcite fragments and reddish-brown mineral particles (max. diam. $0.1 \mathrm{~cm}) »$.

95. E. S. Forster, BSA 11 (1904-1905), p. 243 "light-red clay of the district "; R. A. Higgins, Catalogue of the Terracottas. British Museum I (1954), p. 157 : « lightly fired, usually pale orange, with frequently a brown or cream surface".

96. ERICKSON 2009, p. 365.

97. J. Whitley (n. 91, 2008), p. 245. Voir aussi J. Whitley (n. 91, 2006), p. 613. Le principe est accepté par Pilz 2011, p. 75. 
réfléchir à nouveau sur la distribution de types et sur les identités qui pouvaient y être associées. Il s'agit en effet d'expliquer la raison pour laquelle on trouve dans un sanctuaire de la cité d'Itanos des terres cuites provenant de la cité voisine - et rivale sans doute - alors même que ce matériel est, d'après les spécialistes, caractéristique d'une identité locale, en l'occurrence praisienne et étéocrétoise. L'explication, on va le voir, n'est guère évidente.

Il paraît tout d'abord exclu d'en conclure, comme cela a été fait pour les divers sanctuaires de l'arrière-pays de Sitia, un quelconque contrôle exercé par Praisos sur Itanos à l'époque archaïque ${ }^{98}$. Le sanctuaire de Vamiès, probablement consacré à Déméter, est situé aux portes de la ville. Il est sans doute lié à la polis d'Itanos. Pour cette même raison, il est également difficile d'envisager que les dédicants aient été issus de Praisos plutôt que d'Itanos. Il ne s'agit pas davantage d'offrandes de prestige, pour lesquelles on pourrait plus volontiers imaginer des dédicants étrangers. Tout paraît ainsi indiquer qu'à l'époque archaïque, les habitants d'Itanos pouvaient offrir dans un sanctuaire civique des terres cuites produites dans la cité voisine.

Comme J. Whitley l'a rappelé, les sanctuaires sont un lieu privilégié pour l'expression de multiples formes d'identité collective, en particulier durant les périodes de rivalité entre cités. En l'occurrence, à Praisos, ces terres cuites dédaliques participeraient de la construction à la fois d'une identité civique (liée à la polis de Praisos) et d'une identité ethnique (liée à l'ethnos étéocrétois tel que décrit par les auteurs anciens). L'interprétation repose tant sur l'assemblage particulier et récurrent de plusieurs types dédaliques dans les sanctuaires de la chôra que sur l'absence de ces mêmes types en dehors du territoire de Praisos. Si la découverte à Itanos de ces types dédaliques ne remet pas en question radicalement l'interprétation de J. Whitley, elle oblige pour le moins à la nuancer. Bien entendu, Itanos n'a - pour le moment - livré que trois fragments de terres cuites dédaliques sur le seul sanctuaire de Vamiès, qui doivent être confrontés aux centaines de pièces découvertes dans les multiples lieux de culte du territoire de Praisos. Il paraît toutefois difficile de les ignorer et il faut bien tenter d'en rendre compte. Il est certes possible que la production et la dédicace de ces figurines dédaliques aient été associées, à Praisos, à l'expression d'une identité spécifique, mais il est difficile d'imaginer que l'offrande de ces mêmes figurines ait été associée, à Itanos, à une identité liée à la polis de Praisos. Cela suffit, semble-t-il, à refuser de voir dans l'offrande de ces terres cuites - mais peut-être pas, convenons-en, dans la production - une quelconque logique oppositionnelle de nature civique entre Praisos et sa voisine, comme le suggère J. Whitley.

98. Contra L. Sjögren, Cretan Locations. Discerning Site Variations in Iron Age and Archaic Crete (800-500 B.C.) (2003), p. 45 et 88. L'hypothèse de L. Sjögren ne repose en rien sur l'étude de la petite plastique, mais sur les structures d'occupation du sol. Pour une réfutation, A. DuplouY, «Le territoire d'Itanos au $\mathrm{I}^{\text {er }}$ millénaire av. J.-C. : de la naissance de la cité grecque à la conquête romaine », dans A. ScHnApp (éd.), Le territoire d'Itanos (à paraître). 
Ces terres cuites renvoient-elles par ailleurs à une opposition ethnique entre les deux cités? Les textes eux-mêmes permettent d'en douter, autant que la distribution des types dédaliques. Si aucune des sept inscriptions étéocrétoises connues ${ }^{99}$ (dont deux à Dréros et trois à Praisos) n'a été découverte à Itanos, il faut néanmoins rappeler que l'une des légendes de fondation de la cité lie indiscutablement celle-ci à l'ethnos étéocrétois, au même titre que sa voisine Praisos et par-delà les frontières civiques. Stéphane de Byzance

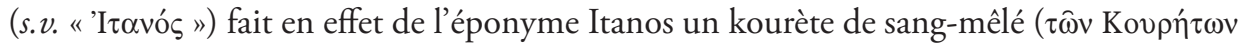
$\dot{\varepsilon} v o ̀ \varsigma \mu\left(\gamma \alpha \dot{\alpha} \delta \varsigma_{\varsigma}\right)^{100}$. Il s'agit certes là d'un témoignage tardif et isolé, dont le contexte est inconnu, mais l'opposition ethnique entre Praisos et sa voisine n'est assurément pas aussi tranchée que le suppose J. Whitley.

Faut-il par ailleurs superposer cette possible identité étéocrétoise commune à Praisos et à Itanos à la carte de distribution des terres cuites dédaliques? L'hypothèse peut être formulée, mais bien des éléments manquent dans notre connaissance des constructions identitaires de Crète de l'Est pour faire des terres cuites dédaliques l'indice ou le marqueur assuré d'une identité ethnique étéocrétoise commune.

Enfin, il faut souligner que la similitude des terres cuites découvertes à Vamiès avec les types attestés dans le territoire de Praisos se limite aux types dédaliques. À partir du $\mathrm{VI}^{\mathrm{e}}$ s., l'assemblage votif découvert à Vamiès ne trouve plus aucun correspondant dans les sanctuaires du territoire de Praisos; il se rapproche davantage, avons-nous vu, d'autres lieux de culte crétois, en particulier des sanctuaires de Cnossos et d'Olonte. À l'inverse, après le floruit de l'époque archaïque, les petits sanctuaires ruraux du territoire de Praisos ne semblent recevoir aucune des séries de terres cuites que l'on retrouve à Vamiès. Les cultes de Praisos ne s'alignèrent en fait jamais sur les modèles étrangers. En ce sens, tandis que Praisos maintient son identité et reste hermétique au monde extérieur, Itanos s'ouvre largement sur celui-ci vers la fin de l'archaïsme, sinon même dès le vi ${ }^{e} \mathrm{~s}$. avec des modèles ioniens et corinthiens, puis attiques. Il s'agit là, malgré l'exiguïté de la collection de terres cuites d'Itanos, d'un élément important à verser au dossier de l'évolution historique, peu à peu divergente, des deux cités, comme l'histoire de leur territoire permet également de s'en rendre compte ${ }^{101}$.

99. Auxquelles il faut maintenant ajouter un graffito archaïque d'Azoria sur une anse de pithos; voir D. C. HAggis et al., "Excavations in the Archaic Civic Buildings at Azoria in 2005-2006 ", Hesperia 80 (2011), p. 1-70, en particulier p. 57-58.

100. Voir déjà L. Mariani, "Antichità cretesi ", MonAnt 6 (1895), col. 313; S. Spyridakis, Ptolemaic Itanos and Hellenistic Crete (1970), p. 6-7. Pareille identité étéocrétoise semble néanmoins avoir coexisté, dans les mythes de fondation d'Itanos, avec une origine phénicienne; voir D. VIVIERs, A. Tsingarida, "Facing the Sea: Cretan Identity in a Harbour-City Context. Some Remarks on the Early Development of Itanos", dans Fl. Gaignerot-Driessen, J. Driessen (éds), Cretan Cities: Formation and Transformation (2014), p. 165-182, en particulier p. 171.

101. On renverra pour cela à l'étude de synthèse d'A. Duplouy (n. 98), à paraître. 
Bien entendu, il ne saurait être question de répondre à la question complexe de la construction des identités locales de Crète de l'Est grâce aux seuls exemples qui nous sont parvenus de la petite plastique de Vamiès. Il nous paraît toutefois intéressant de soulever le problème et de manifester que le lien généralement opéré entre les types dédaliques et une identité précise relève dans une large mesure d'un postulat non démontré. Les trois exemplaires dédaliques de Vamiès, pour modeste que soit la trouvaille, invitent en effet à une relative prudence dans l'interprétation historique. Si le lien entre une identité praisienne et une catégorie spécifique de terres cuites retrouvée dans les sanctuaires de la cité ou de ses environs peut être postulé, d'autres facteurs interviennent assurément pour en expliquer la diffusion ${ }^{102}$. L'étude de ce modeste lot de figurines éclaire donc l'histoire du site et, pour une part, celle de la cité d'Itanos; il invite aussi à nuancer certaines interprétations qui s'attachent à l'étude du matériel crétois d'époque archaïque. Le tableau que nous nous sommes efforcés de dresser du sanctuaire à partir de son architecture et des figurines que l'on y a trouvées demeure toutefois largement incomplet. Le site n’ayant jamais été fouillé, seul nous est accessible un matériel de surface, non stratifié et nécessairement très partiellement recueilli. Pour autant, et malgré le peu d'éléments dont nous disposons pour son interprétation, le dépôt est suffisamment divers pour mériter l'attention que nous lui avons consacrée.

102. Voir sur ce point les réflexions d'A. Duplouy, "L'individu et la cité. Quelques stratégies identitaires et leur contexte ", REA 108 (2006), p. 61-78. 